Research Article

\title{
Chloride Transport Performance of Basalt-Polypropylene Fiber Reinforced Concrete under Drying-Wetting Cycles
}

\author{
Li Su, ${ }^{1}$ Ditao Niu $\mathbb{D}^{1,2}$ Daguan Huang, ${ }^{1}$ and Qiang Fu ${ }^{1,2}$ \\ ${ }^{1}$ School of Civil Engineering, Xi'an University of Architecture and Technology, Xi'an 710055, China \\ ${ }^{2}$ State Key Laboratory of Green Building in Western China, Xi'an University of Architecture and Technology, Xi'an 710055, China \\ Correspondence should be addressed to Ditao Niu; niuditao@163.com
}

Received 20 January 2021; Revised 26 February 2021; Accepted 22 March 2021; Published 5 April 2021

Academic Editor: Peng Zhang

Copyright (c) $2021 \mathrm{Li}$ Su et al. This is an open access article distributed under the Creative Commons Attribution License, which permits unrestricted use, distribution, and reproduction in any medium, provided the original work is properly cited.

\begin{abstract}
This study investigated the chloride transport performance of basalt-polypropylene fiber reinforced concrete (BPFRC) subjected to drying-wetting cycles. The effects of the strength grade, basalt fiber (BF), polypropylene fiber (PF), and hybrid $\mathrm{BF}-\mathrm{PF}$ on the pore solution $\mathrm{pH}$, chloride concentration distribution, chloride peak concentration $\left(C_{\max }\right)$, and apparent chloride diffusion coefficient $\left(D_{\mathrm{a}}\right)$ of the BPFRC were analyzed, and a multifactor model of $D_{\mathrm{a}}$ was established. Moreover, the microstructures of BPFRC were studied to explore the effect of fibers on chloride transport performance of concrete in terms of theoretical pore volume, fiber-matrix interface, fiber bonding properties, and corrosion morphology. The results showed that the chloride concentration of the BPFRC increased and the pore solution $\mathrm{pH}$ of the BPFRC decreased with the increase in the exposure time. The chloride concentration and $D_{\mathrm{a}}$ of the BPFRC decreased with the increase in the strength grade. At a fiber volume content of $0.1 \%$, the addition of $\mathrm{BF}$ and $\mathrm{PF}$ reduced the chloride concentration and $D_{\mathrm{a}}$ of the BPFRC; at a fiber volume content of $0.2 \%$, the addition of hybrid BF-PF increased the chloride concentration and $D_{\mathrm{a}}$ of the concrete. The chloride peak concentration appeared at the depth of $2 \mathrm{~mm}$ inside the concrete, and the change of the chloride peak concentration with exposure time followed the power function model. The theoretical pore volume of the BPFRC specimens decreased initially and then increased with the increase in the exposure time. FE-SEM observed that the bonding property between BF and matrix was better than that of PF, which could effectively control the development of microcracks.
\end{abstract}

\section{Introduction}

Concrete is one of the most widely used building materials in the world [1]. However, its typical quasibrittle characteristics, low tensile strength, and low strain capacity have a significant effect on the application and development of concrete structures $[2,3]$. The addition of short and disorderly distributed fibers can inhibit the generation and development of microcracks in concrete, control the stress at the crack tip, and play a bridging role, thereby significantly improving the toughness of the concrete [4-6] and increasing its application. At present, two types of fibers are mixed into concrete-rigid fibers and flexible fibers. Rigid fibers, such as steel fiber, carbon fiber, and basalt fiber (BF), have high elastic modulus and can improve the strength and bearing capacity of concrete, and steel fiber can increase the ductility of concrete $[7,8]$. Flexible fibers, such as polyethylene fiber and polypropylene fiber (PF), have a low elastic modulus and good chemical stability and ductility and can significantly improve ductility and restrain cracking in concrete $[9,10]$.

To realize the benefits of various types of fibers and save costs, hybrid fibers of similar or different types and sizes have become an important area of research. Hybrid steelpolypropylene fibers are one of the most widely used hybrid fibers at present, and their synergistic effect can significantly improve the mechanical properties and toughness of concrete, while also improving its impermeability [11, 12]. However, hybrid steel-polypropylene fibers have an inherent fatal defect-the chemical composition of steel fiber is 
similar to that of steel bars and is prone to rust in marine environments. Consequently, there is an urgent need to find other rigid fibers to replace steel fibers.

$\mathrm{BF}$ is a new type of environment-friendly fiber that has the advantages of excellent chemical stability, large elastic modulus, good wear resistance, and low cost [13]. It is a suitable replacement for steel fibers in hybrid fiber systems in marine environments. Due to differences in their physical and mechanical properties, the addition of $\mathrm{BF}$ and $\mathrm{PF}$ to concrete can reduce the brittleness of concrete, restrain the development of internal cracks, and improve impermeability [14]. The dispersion of the hybrid fibers in a hybrid fiber system is another important consideration. The addition of admixtures can increase the uniformity of the dispersion of hybrid fibers, improve the bond properties between the fibers and the concrete matrix [15], and improve the durability of concrete [16].

One of the main factors that threaten the durability of concrete structures in marine environments is chloride erosion. Based on the location of a building in a marine environment, the chloride erosion environment can be further divided into marine underwater zone (full immersion) and tidal zone (drying-wetting cycles). Owing to the action of the drying-wetting cycles, the deterioration rate of the structural performance of concrete structures in tidal zone is significantly higher than that in underwater zone, and the diffusion rate of chloride in concrete structures in tidal zone is higher than that in the underwater zone as well [17-19]. Consequently, the time required to reach the chloride concentration limit of steel bar corrosion in concrete is reduced [20], which is very easy to cause steel bar corrosion and shortens the service life of buildings.

At present, most researchers study the durability of basaltpolypropylene fiber reinforced concrete (BPFRC) through rapid chloride permeation and water absorption [16, 21-24]. However, very few studies exist on the chloride transport performance of BPFRC subjected to drying-wetting cycles. In this study, the long-term chloride transport performance of BPFRC subjected to drying-wetting cycles was investigated. The free chloride concentration and pore solution $\mathrm{pH}$ in the BPFRC were measured at various depths, and the effects of the strength grade, $\mathrm{BF}, \mathrm{PF}$, and hybrid BF-PF on pore solution $\mathrm{pH}$, chloride concentration, chloride peak concentration $\left(C_{\max }\right)$, and apparent chloride diffusion coefficient $\left(D_{\mathrm{a}}\right)$ were analyzed. In addition, a multifactor model of $D_{\mathrm{a}}$ was established considering the effects of the exposure time, strength grade, and fibers content (BF and PF). Finally, the microstructures of BPFRC before and after erosion, such as theoretical total pore volume $(P)$, the bonding performance between fiber and concrete matrix, and corrosion morphology, were evaluated by thermogravimetry (TG) and field emission scanning electron microscope (FE-SEM).

\section{Materials and Experimental Methods}

2.1. Raw Materials. The cementitious materials used to prepare the BPFRC specimens included P. O. 42.5 ordinary Portland cement (C), fly ash (FA), silica fume (SF), and granulated blast furnace slag (GGBS). The chemical composition and physical properties of the cementitious materials are listed in Tables 1-3. The appearance of the BF and PF are shown in Figure 1. The length, diameter, density, tensile strength, elastic modulus, elongation, and aspect ratio of the BF, prepared by Aerospace Tuoxin Basalt Industry Co., Ltd., Sichuan, China, were $18 \mathrm{~mm}, 15 \mu \mathrm{m}, 2.56 \mathrm{~g} / \mathrm{cm}^{3}$, $4500 \mathrm{MPa}, 75000 \mathrm{MPa}, 3.15 \%$, and 1200 , respectively, and those of the PF, prepared by Subote New Material Co., Ltd., Jiangsu, China, were $19 \mathrm{~mm}, 30 \mu \mathrm{m}, 0.91 \mathrm{~g} / \mathrm{cm}^{3}, 270 \mathrm{MPa}$, $3000 \mathrm{MPa}, 40 \%$, and 633, respectively. The coarse aggregate (CA) was limestone gravel with a particle size of 5-20 mm and an apparent density of $2.7 \mathrm{~g} / \mathrm{cm}^{3}$. River sand with a fineness modulus and apparent density of 2.8 and $2.63 \mathrm{~g} / \mathrm{cm}^{3}$, respectively, was used as the fine aggregate (S). The mixed water (W) was laboratory tap water. A polycarboxylate superplasticizer (PBS) with a water-reducing rate of $30 \%$ was used.

2.2. Mix Proportions and Specimen Preparation. Seven groups of BPFRC specimens were fabricated. The detailed mix proportions of the BPFRC specimens are shown in Table 4. Groups 1-3 were used to compare the effects of different strength grades using the optimal mix proportions obtained from an orthogonal test. Groups 2 and 4-7 were used to compare the effect of single and hybrid fiber on the chloride transport performance of concrete and were fabricated based on the optimal mix proportion of the strength grade $\mathrm{C} 40$. HC, BC, PC, and $\mathrm{BPC}$ represent concrete without fiber, $\mathrm{BF}$ reinforced concrete, $\mathrm{PF}$ reinforced concrete, and hybrid BF-PF reinforced concrete, respectively. BF and PF are mixed such that equal volume content is obtained. The first group of numbers after the letters indicates the concrete strength grade and the second group of numbers indicates the fiber volume content. For example, BPC-30-0.1 denotes the fact that the fiber type is hybrid $\mathrm{BF}$ and $\mathrm{PF}$, the concrete has a strength grade of $\mathrm{C} 30$, and the fiber volume content is $0.1 \%$.

The mixing process of the BPFRC was as follows:

(i) The dried CA and S were poured into the mixer and mixed for $30 \mathrm{~s}$;

(ii) Cementitious materials (C, FA, SF, and GGBS) were added and stirred for $2 \mathrm{~min}$;

(iii) $\mathrm{PF}$ and $\mathrm{BF}$ were added to the mix and stirred for $2 \mathrm{~min}$ and $3 \mathrm{~min}$, respectively;

(iv) $\mathrm{W}$ and PBS were poured into the mixture and stirred for $2 \mathrm{~min}$.

The evenly mixed concrete mixtures were poured into $100 \mathrm{~mm} \times 100 \mathrm{~mm} \times 100 \mathrm{~mm}$ cube molds and vibrated on a shaking table for $15 \mathrm{~s}$. After $24 \mathrm{~h}$, the specimens were demolded and placed in a standard curing room maintained at a temperature of $(20 \pm 2)^{\circ} \mathrm{C}$ and a humidity of $95 \%$ for $28 \mathrm{~d}$. Subsequently, the chloride diffusion test was conducted.

\subsection{Experiment and Testing Methods}

2.3.1. Chloride Drying-Wetting Cycle Test. High temperature and drying-wetting cycles were used to simulate the extreme 
TABLE 1: Chemical composition of cementitious materials.

\begin{tabular}{|c|c|c|c|c|c|c|c|c|c|}
\hline Composition (wt. \%) & $\mathrm{SiO}_{2}$ & $\mathrm{Al}_{2} \mathrm{O}_{3}$ & $\mathrm{Fe}_{2} \mathrm{O}_{3}$ & $\mathrm{CaO}$ & $\mathrm{MgO}$ & $\mathrm{SO}_{3}$ & $\mathrm{~K}_{2} \mathrm{O}$ & $\mathrm{Na}_{2} \mathrm{O}$ & $\mathrm{MnO}$ \\
\hline $\mathrm{C}$ & 21.18 & 5.02 & 3.14 & 63.42 & 3.12 & 2.3 & 0.65 & 0.42 & 0.05 \\
\hline FA & 35.71 & 16.57 & 8.92 & 21.14 & 1.41 & 1.94 & 2.18 & 1.02 & 0.1 \\
\hline SF & 85.04 & 0.97 & 1.04 & 1.63 & 0.32 & - & 0.81 & 0.19 & 0.32 \\
\hline GGBS & 34.65 & 14.21 & 0.49 & 34.11 & 11.15 & 1.01 & 0.30 & 0.35 & 0.21 \\
\hline
\end{tabular}

TABLe 2: Physical and mechanical properties of cement.

\begin{tabular}{|c|c|c|c|c|c|c|c|c|c|}
\hline \multirow[t]{2}{*}{ Density $\left(\mathrm{g} / \mathrm{cm}^{3}\right)$} & \multirow[t]{2}{*}{$\begin{array}{c}\text { Specific area } \\
\text { surface }\left(\mathrm{m}^{2} / \mathrm{kg}\right)\end{array}$} & \multirow[t]{2}{*}{ Fineness (\%) } & \multirow[t]{2}{*}{ Ignition loss (\%) } & \multicolumn{2}{|c|}{ Setting time $(\mathrm{h})$} & \multicolumn{2}{|c|}{$\begin{array}{l}\text { Compressive } \\
\text { strength } \\
(\mathrm{MPa})\end{array}$} & \multicolumn{2}{|c|}{$\begin{array}{c}\text { Flexural } \\
\text { strength } \\
(\mathrm{MPa})\end{array}$} \\
\hline & & & & Initial & Final & $3 \mathrm{~d}$ & $28 \mathrm{~d}$ & $3 \mathrm{~d}$ & $28 \mathrm{~d}$ \\
\hline 3.10 & 334 & 3.8 & 2.79 & 2.3 & 3.4 & 28.8 & 48.6 & 6.4 & 8.6 \\
\hline
\end{tabular}

TABLE 3: Physical properties of admixtures.

\begin{tabular}{lccc}
\hline Type & FA & SF & GGBS \\
\hline Water content $(\%)$ & 0.2 & 0.06 & 0.7 \\
Density $\left(\mathrm{g} / \mathrm{cm}^{3}\right)$ & 2.35 & 2.10 & 2.86 \\
Ignition loss $(\%)$ & 2.85 & 5.48 & 0.31 \\
Specific area surface $\left(\mathrm{m}^{2} / \mathrm{kg}\right)$ & 340 & 23000 & 410 \\
Fineness $(\%)$ & 17 & - & - \\
Average particle size $(\mu \mathrm{m})$ & - & 0.12 & 14.5 \\
\hline
\end{tabular}

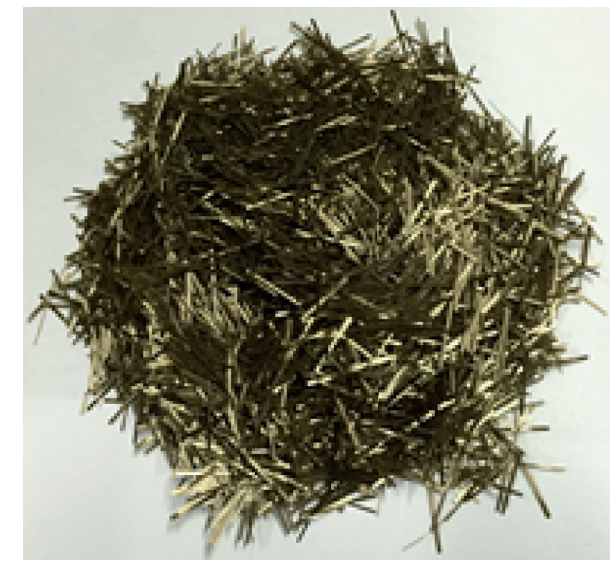

(a)

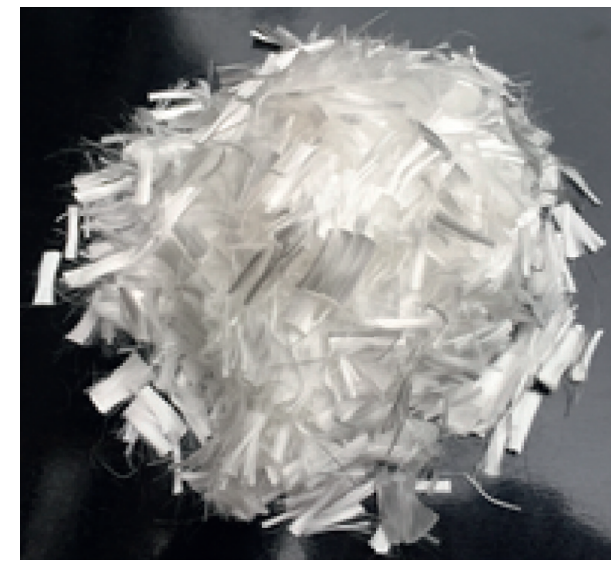

(b)

Figure 1: Morphology of fibers. (a) Basalt fiber. (b) Polypropylene fiber.

TABle 4: Mix proportions of BPFRC $\left(\mathrm{kg} / \mathrm{m}^{3}\right)$.

\begin{tabular}{|c|c|c|c|c|c|c|c|c|c|c|c|c|}
\hline & Mixture & $\mathrm{C}$ & SF & FA & GGBS & PBS & W & $\mathrm{W} / \mathrm{C}$ & $S$ & CA & $\mathrm{BF}$ & $\mathrm{PF}$ \\
\hline 1 & BPC-30-0.1 & 234.2 & 22 & 73.2 & 36.6 & 3.66 & 161 & 0.44 & 683 & 1162.9 & 1.3 & 0.5 \\
\hline 2 & BC-40-0.1 & 241.6 & 15.8 & 79.2 & 59.4 & 3.96 & 150.5 & 0.38 & 683.4 & 1163.6 & 2.6 & 0 \\
\hline 3 & BC-50-0.05 & 333.1 & 29 & 48.3 & 72.4 & 4.83 & 140 & 0.29 & 774.1 & 1026.1 & 1.3 & 0 \\
\hline 4 & HC-40 & 241.6 & 15.8 & 79.2 & 59.4 & 3.96 & 150.5 & 0.38 & 683.4 & 1163.6 & - & - \\
\hline 5 & PC-40-0.1 & 241.6 & 15.8 & 79.2 & 59.4 & 3.96 & 150.5 & 0.38 & 683.4 & 1163.6 & - & 0.9 \\
\hline 6 & BPC-40-0.1 & 241.6 & 15.8 & 79.2 & 59.4 & 3.96 & 150.5 & 0.38 & 683.4 & 1163.6 & 1.3 & 0.5 \\
\hline 7 & BPC-40-0.2 & 241.6 & 15.8 & 79.2 & 59.4 & 3.96 & 150.5 & 0.38 & 683.4 & 1163.6 & 2.6 & 0.9 \\
\hline
\end{tabular}


heat and humidity of ocean tidal zones. Before the experiment, an epoxy resin was used to seal each specimen, leaving only one surface free as the erosion surface, to study the chloride transport in one-dimensional space. The specimens were immersed in a closed box filled with $\mathrm{NaCl}$ solution (at a temperature of $28^{\circ} \mathrm{C}$ and a concentration of $3.5 \%$ ) for $1 \mathrm{~d}$ and then dried at $50^{\circ} \mathrm{C}$ for $1 \mathrm{~d}$, as shown in Figure 2. Five drying-wetting cycle durations were simulated, including $30 \mathrm{~d}$ (15 cycles), $60 \mathrm{~d}$ (30 cycles), $90 \mathrm{~d}$ (45 cycles), $120 \mathrm{~d}$ (60 cycles), and $180 \mathrm{~d}$ (90 cycles). As the immersion temperature was higher than the general environment, the $\mathrm{NaCl}$ solution was replaced every $5 \mathrm{~d}$ to ensure a constant concentration of solution. After the drying-wetting cycles test, the specimens were ground in layers using a grinder $(1-10 \mathrm{~mm}, 1$ layer/1 mm; 11-20 mm, 1 layer $/ 2 \mathrm{~mm}$ ) and passed through a $0.16 \mathrm{~mm}$ sieve. The powder was stored in a sealed bag for chloride concentration, pore solution $\mathrm{pH}$, and TG testing.

\subsubsection{Chloride Concentration and Pore Solution pH Testing.} The free chloride concentration and pore solution $\mathrm{pH}$ in the BPFRC were measured using the solid-liquid extraction method [25] and the potentiometric method [26]. Solidliquid extraction is the operation of separating substances from solids by liquid; that is, the eroded concrete powder is soaked in deionized water, the chloride ion is dissolved in deionized water after soaking for a corresponding time, and the filtrate is extracted by filtration. The test procedure is shown in Figure 3. The chloride ion concentration in the filtrate was measured using PXSJ-216F titrator with chloride ion electrode and saturated potassium sulfate reference electrode. The free chloride concentration in the BPFRC was calculated as follows:

$$
W_{C^{-}}=\frac{M \times 10^{-p X} \times V}{G} \times 100 \% \text {, }
$$

where $W_{\mathrm{Cl}}{ }^{-}$is the concentration of free chloride in the BPFRC specimen, $\% ; M$ is the molar mass of a chloride ion, $35.45 \mathrm{~g} / \mathrm{mol} ; p X$ is the negative logarithm of the free chloride concentration; $V$ is the deionized water volume during immersion, $100 \mathrm{ml}$; and $G$ is the mass of the soaked powder, $5.000 \mathrm{~g}$.

2.3.3. Thermogravimetric Testing. The thermogravimetric differential scanning of the BPFRC samples subjected to various drying-wetting cycle durations was performed using a METTLER TOLEDO TGA/DSC 2. The mass of the test sample was $15 \mathrm{mg}$, the heating rate was $10{ }^{\circ} \mathrm{C} / \mathrm{min}$, the heating range was $30-900^{\circ} \mathrm{C}$, and the protective gas used during the test was $\mathrm{N}_{2}$ (99\% purity).

2.3.4. Porosity Testing. Diamond [27] demonstrated that the theoretical total pore volume of concrete can be evaluated based on the mass loss of the sample measured by TG. Although the detailed pore size distribution is not obtained, this method serves as an evaluation method to characterize the pore structure of concrete $[27,28]$. The theoretical pore volume calculation method established by Diamond is only suitable for mortar specimens; for concrete specimens, the influence of the coarse aggregate must be considered. Consequently, the equation to calculate the theoretical pore volume of concrete is as follows:

$$
\begin{aligned}
P(\%) & =\frac{V_{p}}{V_{w}+V_{G}} \times 100 \%=\frac{M_{w}-(\mathrm{BW} / 1.3)}{M_{w}+\left(M_{G} / \rho_{G}\right)} \times 100 \%, \\
\frac{M_{G}}{\rho_{G}} & =\frac{M_{c}}{\rho_{c}}+\frac{M_{\mathrm{FA}}}{\rho_{\mathrm{FA}}}+\frac{M_{\mathrm{SF}}}{\rho_{\mathrm{SF}}}+\frac{M_{\mathrm{GGBS}}}{\rho_{\mathrm{GGBS}}}+\frac{M_{\mathrm{CA}}}{\rho_{\mathrm{CA}}}+\frac{M_{S}}{\rho_{S}}, \\
\mathrm{BW}(\%) & =\frac{M_{50}-M_{550}}{M_{550}} \times 100 \%,
\end{aligned}
$$

where $P$ is the theoretical pore volume, $V_{\mathrm{P}}$ is the volume of pores, $V_{\mathrm{W}}$ is the volume of the mixing water, $V_{\mathrm{G}}$ is the volume of the other components (including C, FA, SF, GGBS, CA, and S), $M_{\mathrm{W}}$ is the mass of the mixing water, $M_{\mathrm{G}}$ is the mass of all the other components except water (including $\mathrm{C}, \mathrm{FA}, \mathrm{SF}, \mathrm{GGBS}, \mathrm{CA}$, and $\mathrm{S}), \rho_{\mathrm{G}}$ represent the density values of the C, FA, SF, GGBS, CA, and S, respectively, $\mathrm{BW}$ is the content of the bound water and 1.3 is the average density of $B W$ [29], $M_{\mathrm{C}}, M_{\mathrm{FA}}, M_{\mathrm{SF}}, M_{\mathrm{GGBS}}, M_{\mathrm{CA}}$, and $M_{\mathrm{S}}$ are the masses of the C, FA, SF, GGBS, CA, and S, respectively, $\rho_{C}, \rho_{F A}, \rho_{S F}, \rho_{G G B S}, \rho_{C A}$, and $\rho_{S}$ are the densities of C, FA, SF, GGBS, CA, and S, respectively, and $M_{50}$ and
$M_{550}$ represent the mass values of sample measured by TG at $50^{\circ} \mathrm{C}$ and $550^{\circ} \mathrm{C}$.

2.3.5. Microscopic Testing. After $0 \mathrm{~d}$ and $180 \mathrm{~d}$ of erosion, the BPFRC specimens were broken, and the mortar fragments with diameter of approximately $5 \mathrm{~mm}$ and smooth neat surface were selected as the test samples. During the test, the sample was first adhered to the bracket with double-sided conductive adhesive, and then the sample was sprayed with gold. Finally, the distribution of fibers in concrete and the microstructure of eroded concrete were observed using Zeiss GeminiSEM 500 FE-SEM. 


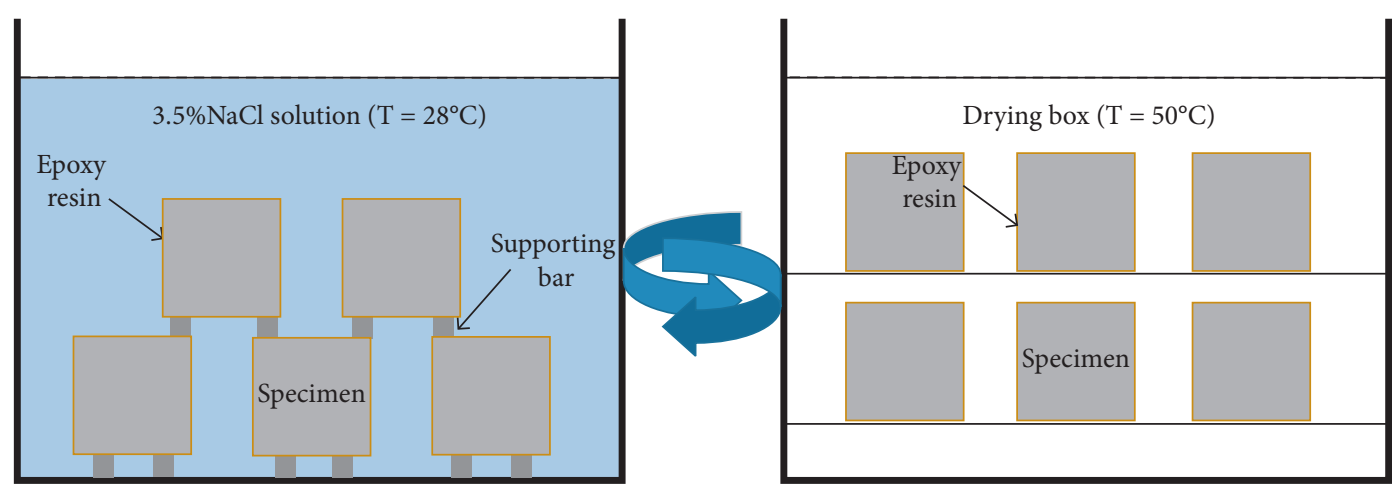

FIGURE 2: Schematic diagram of drying-wetting cycle test.

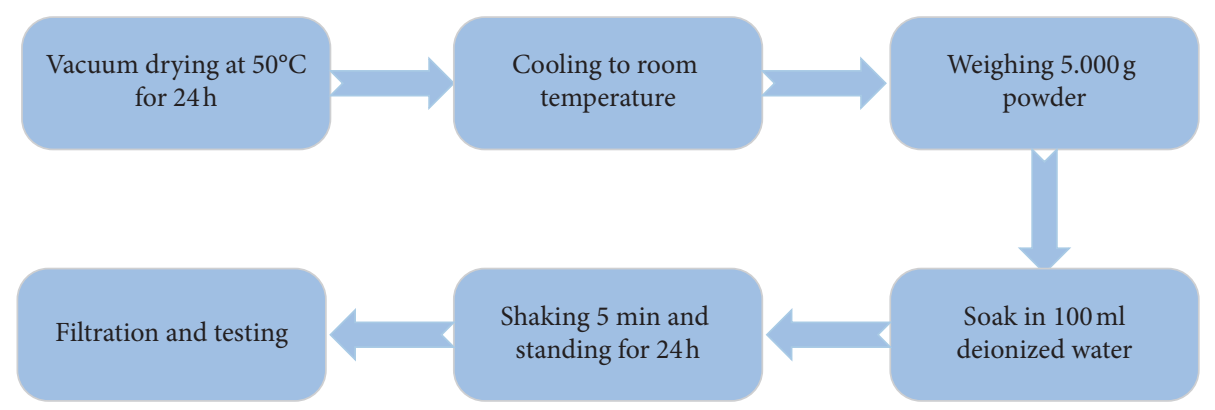

Figure 3: Testing process of pore solution $\mathrm{pH}$ and chloride concentration.

\section{Results and Discussion}

\subsection{Pore Solution $p H$ of BPFRC Subjected to Drying-Wetting Cycles}

3.1.1. Effect of Strength Grade on Pore Solution $p H$. The pore solution $\mathrm{pH}$ of the BPFRC specimens with different strength grades is shown in Figure 4. As shown, the $\mathrm{pH}$ gradually decreases with an increase in the exposure time. This is because, in order to balance the anion charge during the erosion, $\mathrm{OH}^{-}$ions dissolve out while chloride ions enter the concrete through capillary adsorption and diffusion, leading to a continuous decrease in the pore solution $\mathrm{pH}$ [30]. The higher strength grade for the BPFRC results in a higher $\mathrm{pH}$ value. The $\mathrm{pH}$ value at the $1 \mathrm{~mm}$ depth of C50 concrete is $2.43 \%-3.77 \%$ higher than that of the C30 concrete. During the drying-wetting cycle, the rate of reduction in the $\mathrm{pH}$ is slower, and the rising range of $\mathrm{pH}$ is small. After $180 \mathrm{~d}$ of exposure time, the $\mathrm{pH}$ value at a depth of $2 \mathrm{~mm}$ on concrete surface decreases from 11.92 of C50 concrete (BP-50-0.05) to 11.60 of C30 concrete (BPC-30-0.1). With the decrease in the strength grade, the porosity increased. During the drying process, the water in the pores evaporated more easily, and the concrete saturation decreased. During the subsequent wetting process, capillary adsorption was enhanced, and chloride ion exchange increased. Therefore, the pore solution $\mathrm{pH}$ of the low-strength grade BPFRC decreased rapidly.

3.1.2. Effect of Fibers on Pore Solution $p H$. The effect of BF, $\mathrm{PF}$, and hybrid $\mathrm{BF}-\mathrm{PF}$ on the pore solution $\mathrm{pH}$ of $\mathrm{C} 40$ concrete is shown in Figure 5. It can be seen from Figure 5 5 (a) that the $\mathrm{pH}$ value of HC-40 concrete after $180 \mathrm{~d}$ of erosion is significantly lower than that after $120 \mathrm{~d}$, especially at the depth of 3-10 $\mathrm{mm}$. The main reason is that chloride enters into the concrete through capillary adsorption and diffusion in the process of continuous drying-wetting cycle, and the chloride concentration at different depths increases with the increase of erosion time. When chloride ions enter into the concrete, $\mathrm{Ca}^{2+}$ in the alkaline material will dissolve, which makes the hydration products decompose due to decalcification, resulting in the $\mathrm{pH}$ value of concrete to be greatly reduced in the later stage of erosion. With the addition of fiber, the pore size distribution of concrete is wider, which leads to the more prominent "ink bottle effect" in the process of drying-wetting cycle, and the more difficult evaporation and adsorption of water in concrete. Therefore, the decline of $\mathrm{pH}$ of fiber concrete is uniform in the process of erosion. At a depth of $2 \mathrm{~mm}$ below the surface of the specimen, the $\mathrm{pH}$ value of the specimen without fiber was the highest at $30 \mathrm{~d}$ of erosion time, which was 12.13 , and the $\mathrm{pH}$ value of the specimen with $0.1 \% \mathrm{BF}$ was the highest at $180 \mathrm{~d}$ of erosion time, which was 11.75 . When the fiber volume content was $0.1 \%$, the addition of $\mathrm{BF}, \mathrm{PF}$, and hybrid BF-PF increased the $\mathrm{pH}$ value at $180 \mathrm{~d}$ of exposure time, while a hybrid fiber content of $0.2 \%$ reduced the $\mathrm{pH}$ value of the concrete. The results demonstrate that an appropriate fiber content, whether BF or PF alone, or hybrid BF-PF, can inhibit the decrease in the pore solution $\mathrm{pH}$ during the later stages of erosion. This is because an appropriate amount of fiber can optimize the pore size distribution and reduce the 


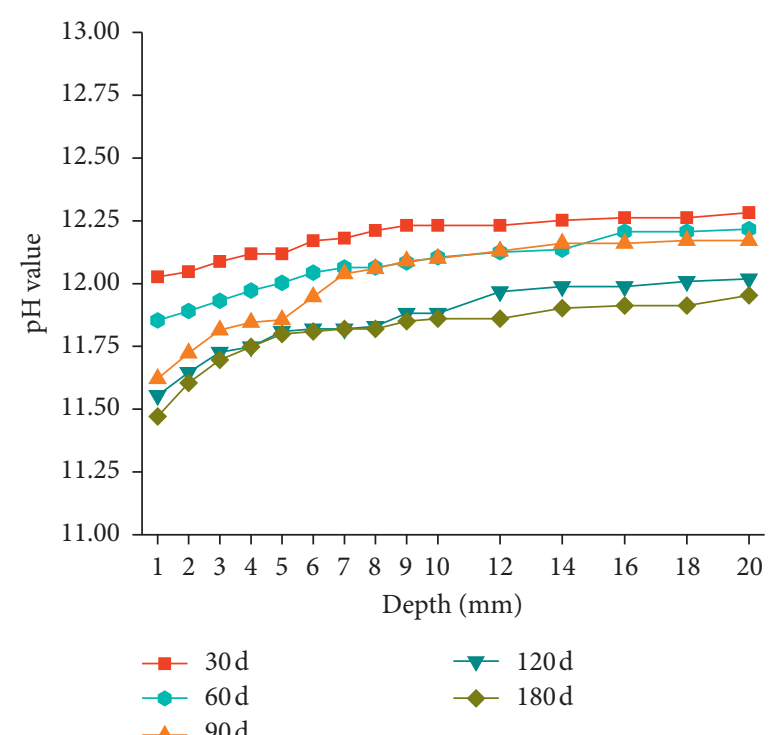

(a)

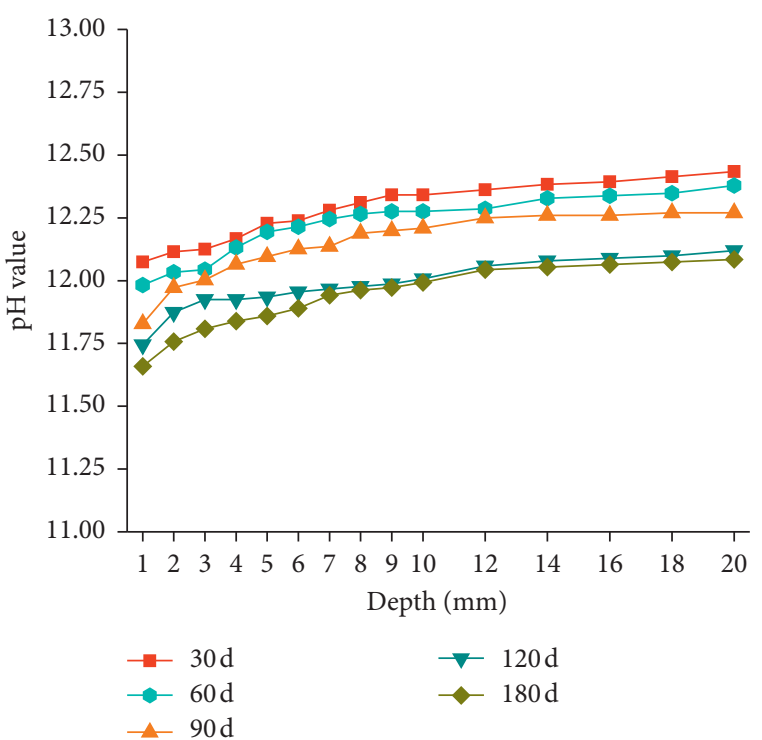

(b)

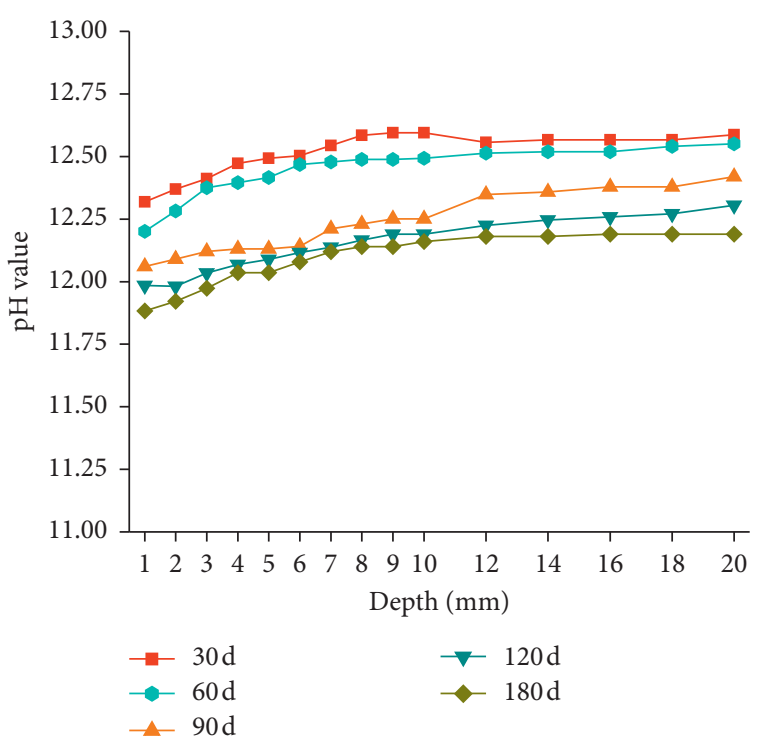

(c)

FIgURe 4: Pore solution pH of BPFRC with different strength grades. (a) BPC-30-0.1. (b) BC-40-0.1. (c) BC-50-0.05.

porosity and degree of anion exchange. With a high fiber content, the interface between the fiber and the matrix increases, a loose matrix and pores are formed around the fiber, the compactness of the concrete decreases, the capillary pore increases $[31,32]$, the chloride diffusion rate increases, the dissolution of alkaline substances increases, and the pore solution $\mathrm{pH}$ decreases rapidly during the process of erosion.

\subsection{Chloride Concentration of BPFRC Subjected to Drying- Wetting Cycles}

3.2.1. Effect of Strength Grade on Chloride Concentration. The chloride concentration distribution in the BPFRC specimens with different strength grades is shown in Figure 6. The chloride concentration increased from the concrete surface, and the $C_{\max }$ and convection zone appeared at a depth of $2 \mathrm{~mm}$ from the concrete surface; subsequently, it decreased and stabilized. The chloride concentration at each depth gradually increased the exposure time, but the increasing range gradually decreased. At a depth of $4 \mathrm{~mm}$ in BPC-30-0.1 specimen, the chloride concentration after $60 \mathrm{~d}$ of erosion was $15.72 \%$ higher than that after $30 \mathrm{~d}$ of erosion, while the chloride concentration after $180 \mathrm{~d}$ of erosion was $4.83 \%$ higher than that after $120 \mathrm{~d}$ of erosion. This is because the hydration of cementitious materials was still in progress during the drying-wetting cycles, decreasing the penetration rate of the chloride ions [33].

As the strength grade increased, the chloride concentration at a given depth in the concrete decreased, the chloride distribution curve was smoother, and the chloride diffusion range was smaller. After $30 \mathrm{~d}$ of erosion, the 

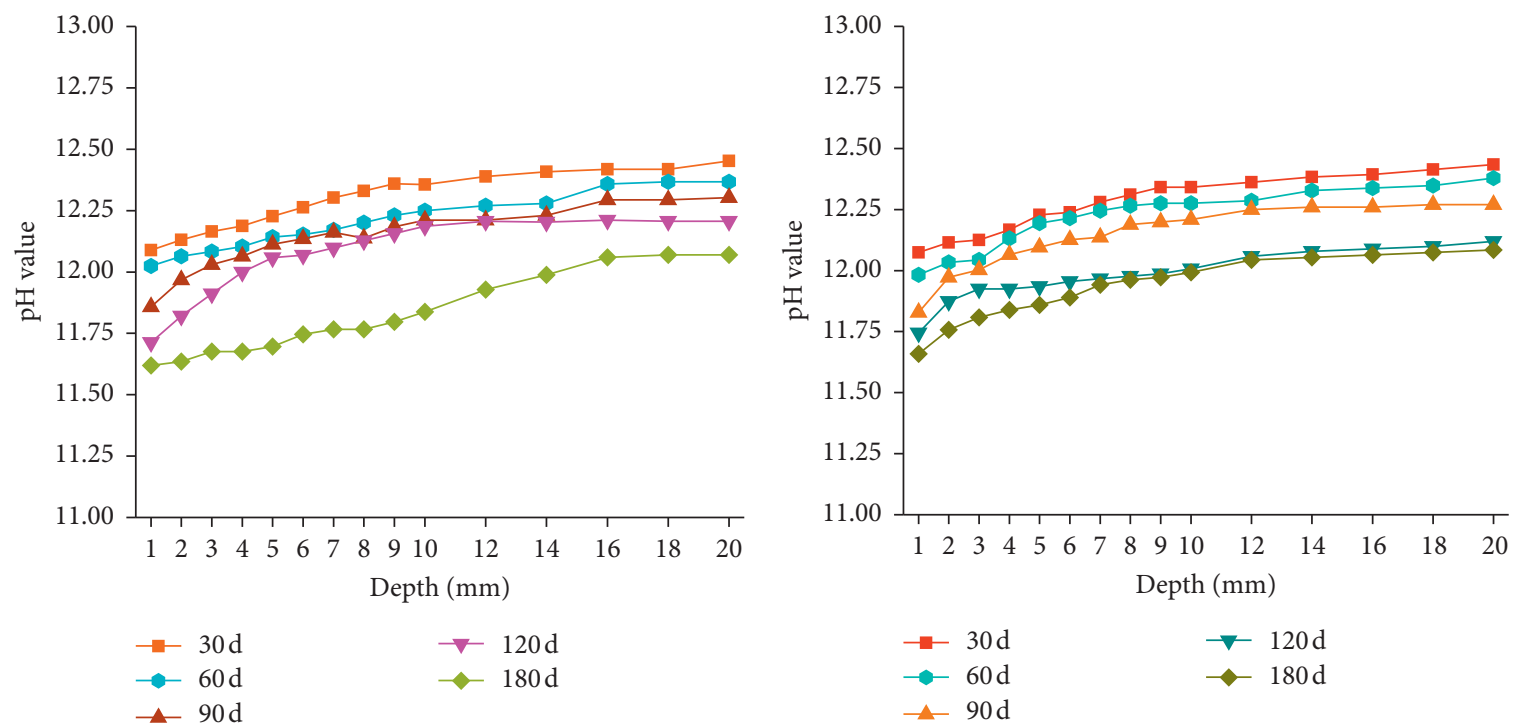

(a)
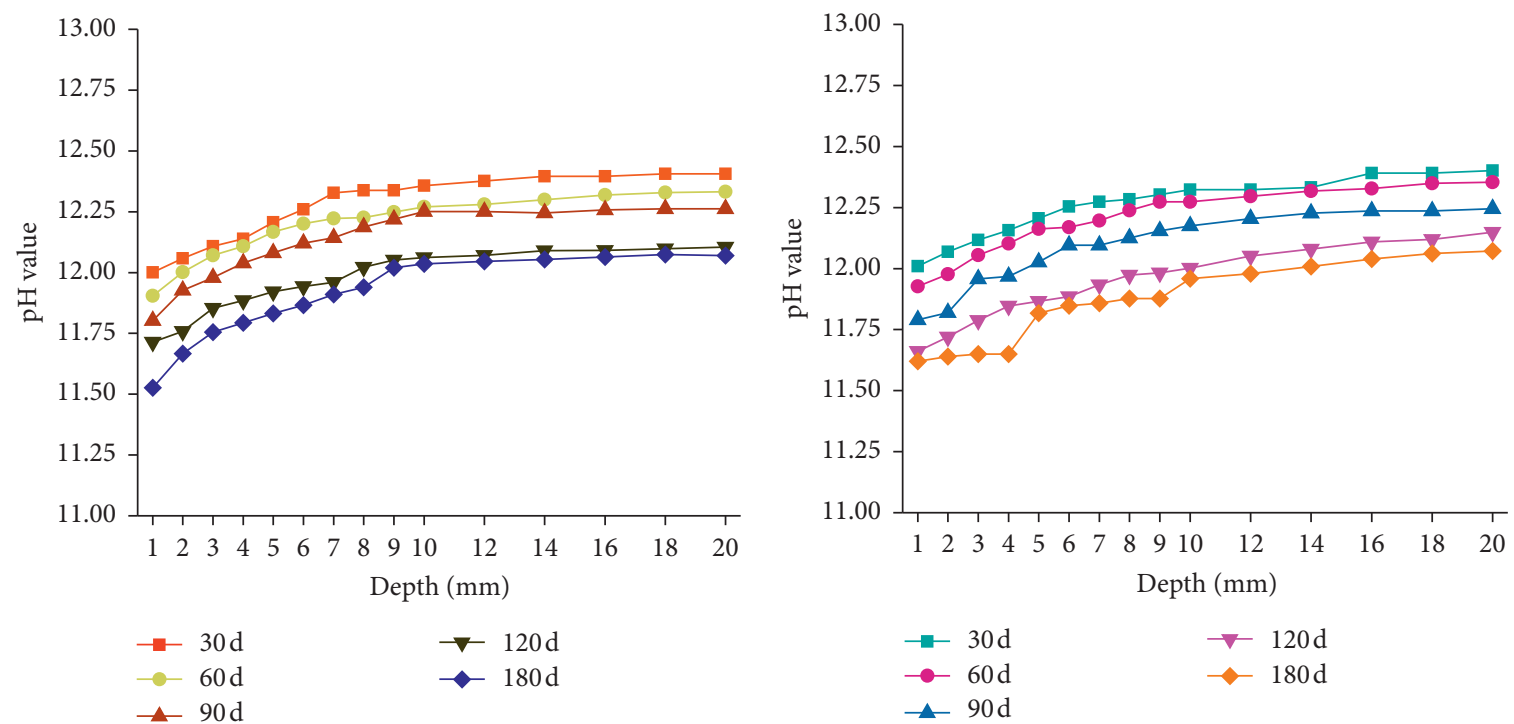

(c)

(d)

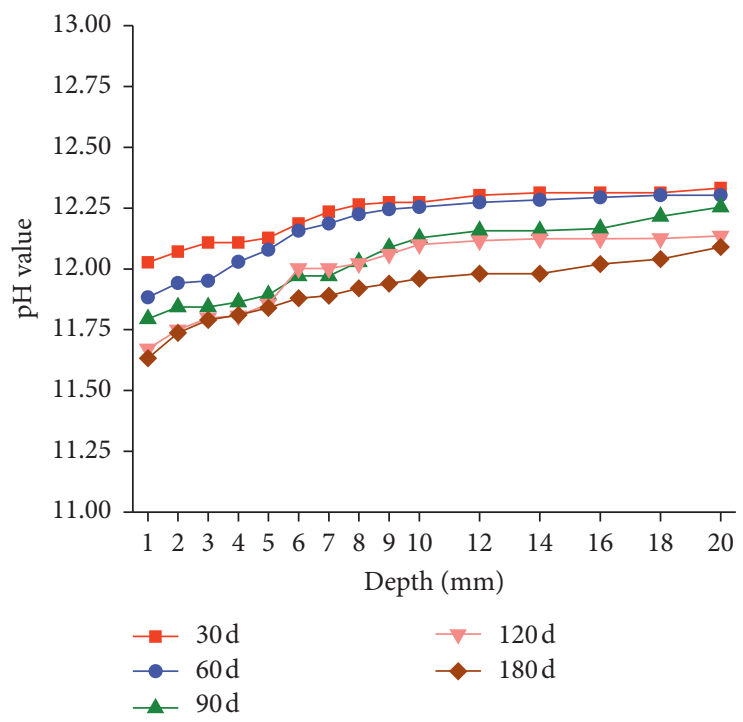

(e)

Figure 5: Pore solution pH of C40 concrete with different fiber type and content. (a) HC-40. (b) BC-40-0.1. (c) PC-40-0.1. (d) BPC-40-0.1. (e) BPC-40-0.2 


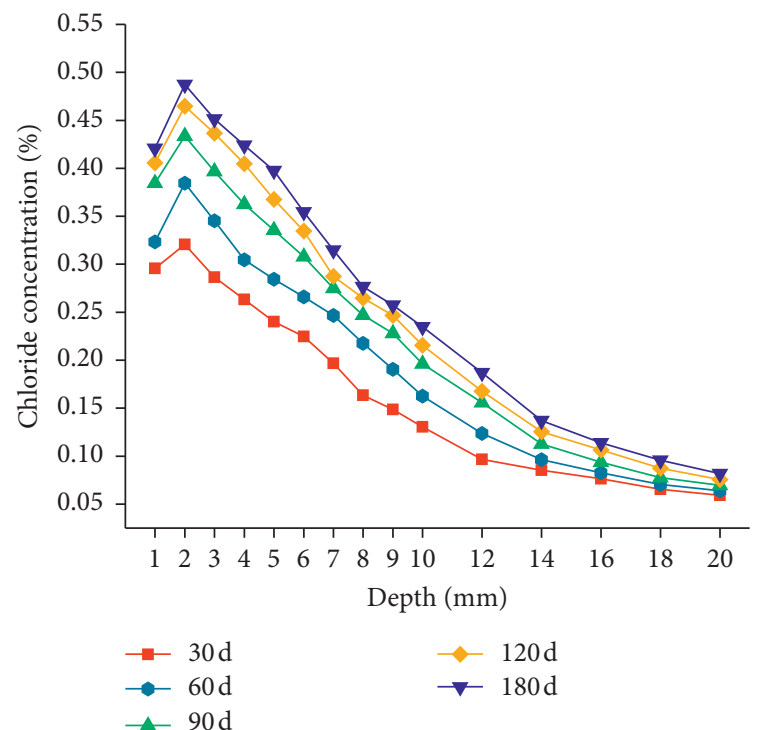

(a)

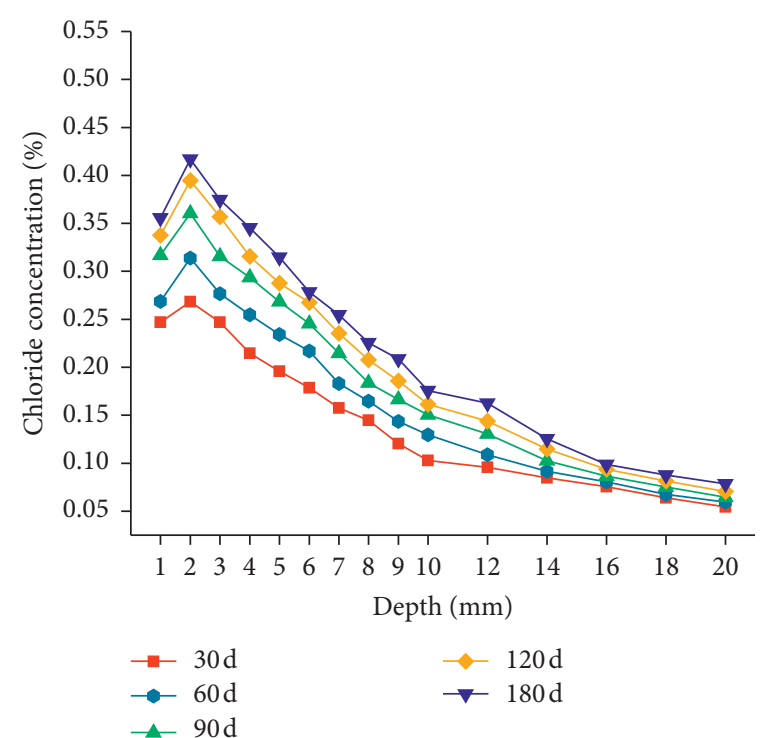

(b)

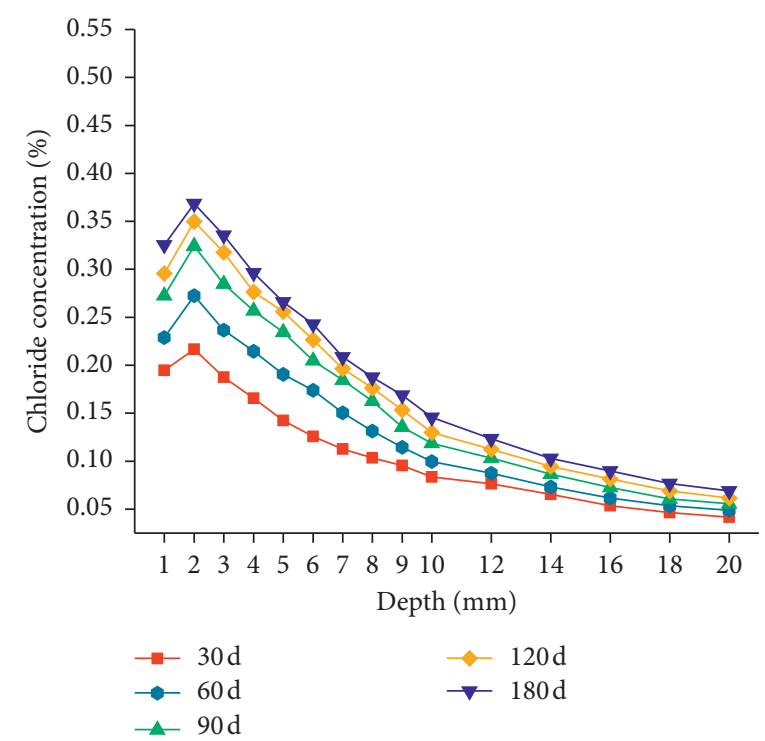

(c)

Figure 6: Chloride concentration distribution of BPFRC with different strength grades. (a) BPC-30-0.1. (b) BC-40-0.1. (c) BC-50-0.05.

chloride concentration at a depth of $2 \mathrm{~mm}$ decreased from $0.32 \%$ of C30 concrete (BPC-30-0.1) to $0.21 \%$ of C50 concrete (BC-50-0.05), a decrease of 34.4\%. However, after $180 \mathrm{~d}$ of erosion, the chloride concentration decreased from $0.48 \%$ of C30 concrete (BPC-30-0.1) to $0.36 \%$ of C50 concrete (BC$50-0.05$ ), a decrease of $25 \%$. The porosity of BPFRC with low strength is higher, and the transport rate of chloride is faster in the wetting process. In the drying process, the water in the pores of low-strength concrete is easier to evaporate, the drying degree of surface concrete is greater, and the capillary negative pressure is higher. Therefore, in the next wetting process, the capillary adsorption is obvious, and more chloride ions enter into the concrete [34].
3.2.2. Effect of Fibers on Chloride Concentration. The effect of $\mathrm{BF}, \mathrm{PF}$, and hybrid BF-PF on the chloride concentration distribution in the BPFRC specimens is shown in Figure 7. At a fiber content of less than $0.1 \%$, the addition of fiber hindered the entry of chloride ions into the concrete. However, when BF and PF were mixed, and the fiber content reached $0.2 \%$, the chloride ion entry into the concrete accelerated. Considering the various erosion times, the order of the BPFRC chloride concentration from low to high was as follows: BC-40-0.1<BPC-40-0.1< PC-40-0.1< HC-40 $<$ BPC-40-0.2. At the same volume content, the effect of the hybrid BF-PF on the chloride concentration at a given depth in the concrete was between those of the two fibers acting 

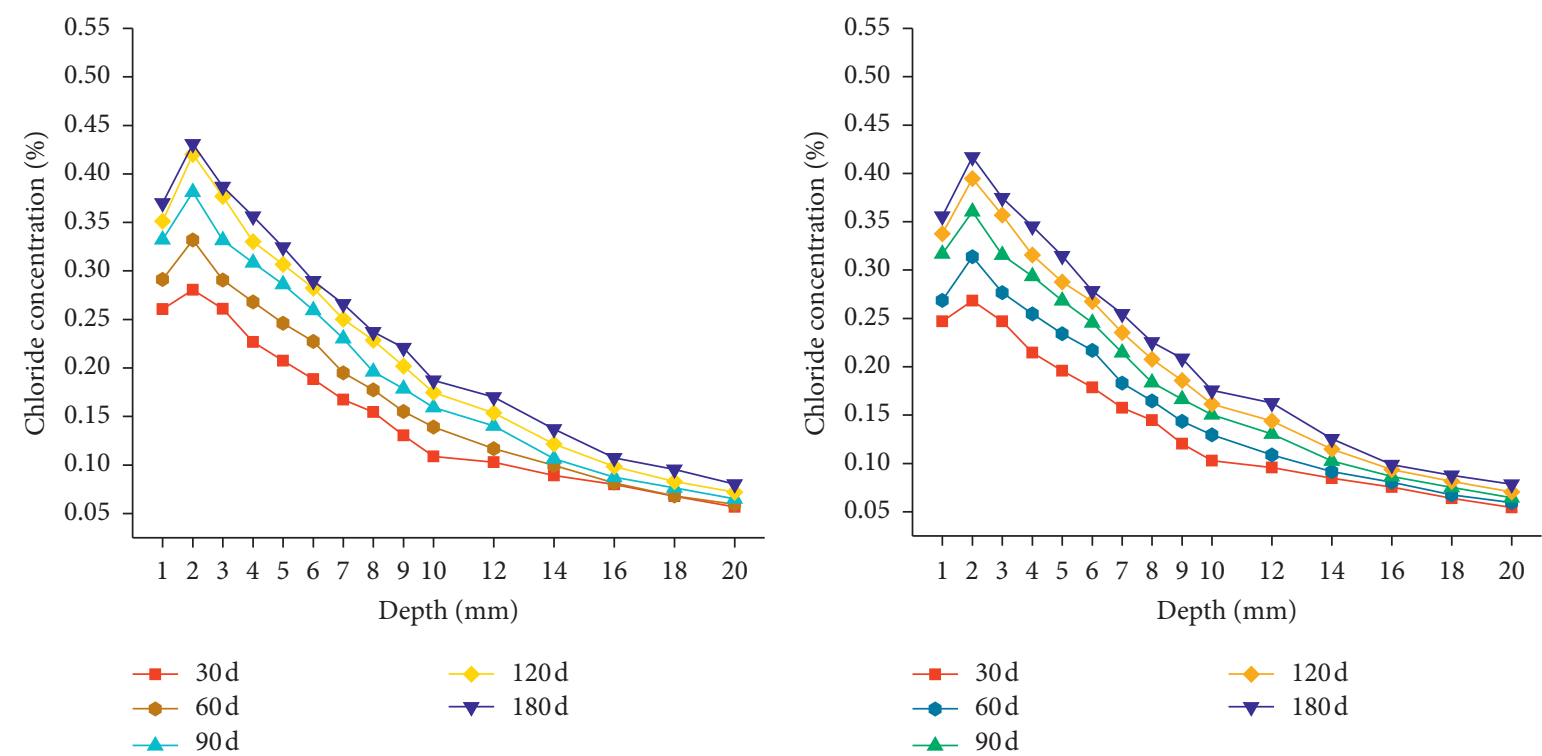

(a)

(b)
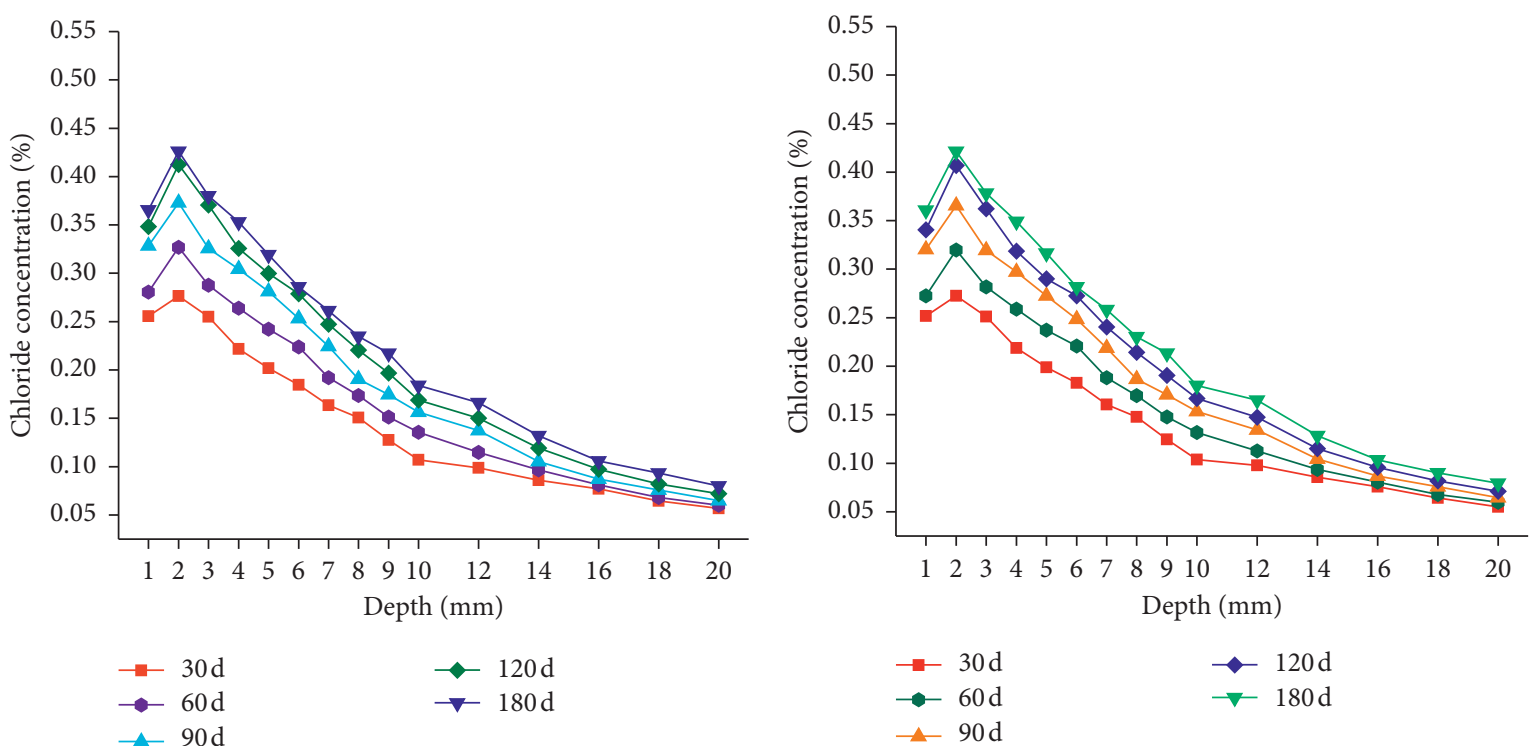

(c)

(d)

FIgURE 7: Continued. 


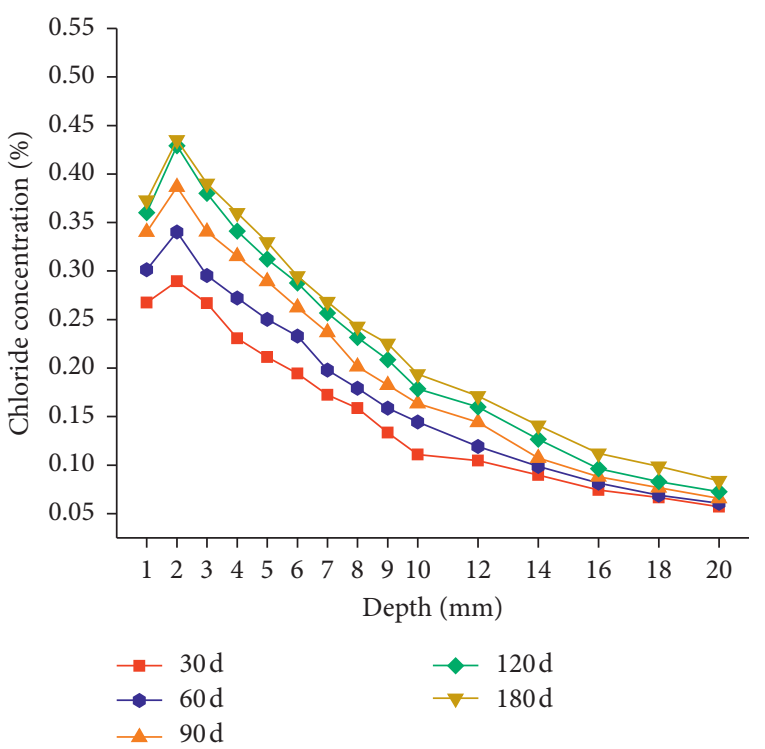

(e)

Figure 7: Chloride concentration distribution of C40 concrete different fiber type and content. (a) HC-40. (b) BC-40-0.1. (c) PC-40-0.1. (d) BPC-40-0.1. (e) BPC-40-0.2.

alone. After 30-180 d of erosion, the chloride concentration at a depth of $2 \mathrm{~mm}$ in BC-40-0.1, PC-40-0.1, BPC-40-0.1, and BPC-40-0.2 concrete was $6.07 \%-3.26 \%$, 2.19\%-1.11\%, $4.07 \%-2.21 \%$, and $-3.2 \%$ to $-0.91 \%$ lower than HC-40 concrete, respectively. This is because the hybrid fiber content was excessive, the fiber dispersion decreased, the BF introduced more pores, and the bond performance between $\mathrm{PF}$ and the concrete matrix decreased, resulting in an increase in the number of internal defects in the concrete [35]. Therefore, the capillary effect of concrete during the erosion increased, the chloride concentration in the convection zone was higher, and the diffusion driving force increased, leading to an increase in the chloride concentration at a given depth.

3.3. Chloride Peak Concentration of BPFRC. Concrete structures located in the ocean tidal zone are usually in an unsaturated state. Chloride ions accumulate on the surface due to the evaporation of pore liquids and the convection of chloride ions, forming a peak concentration in the convection zone. This acts as the driving force for chloride diffusion inside the concrete structure. The chloride concentration deep inside the concrete also increases accordingly. Figure 8 presents $C_{\max }$ of seven groups of BPFRC at different exposure times. It can be seen that although $C_{\max }$ exhibits fluctuations randomly with the strength grade, fiber type, and content varying, $C_{\max }$ of each group of concrete fluctuates within $\pm 15 \%$ of the average value at different exposure times. With the increase of exposure time, $C_{\max }$ of BPFRC gradually increases, but the increasing range gradually decreases and finally tends to be stable. Therefore, the change of $C_{\max }$ of BPFRC is time-dependent. Some studies have shown that the variation of $C_{\max }$ with time can be described as linear, power, exponential, square root, and logarithmic functions [36-39].

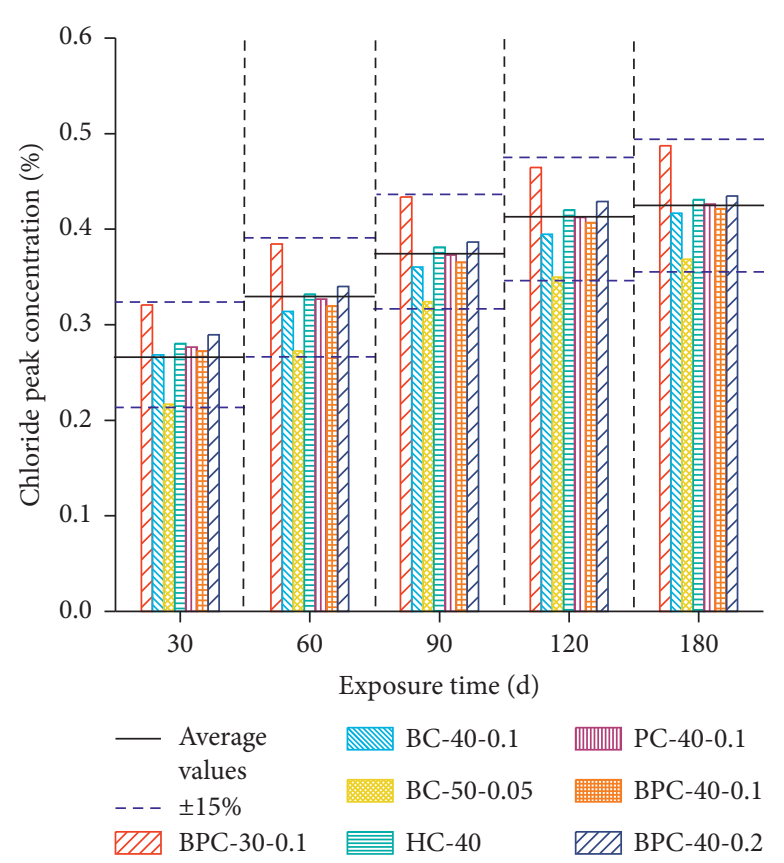

FIgURE 8: Chloride peak concentration of BPFRC at different exposure time.

The above five functions were used to fit the average value of $C_{\max }$ of BPFRC specimens with the exposure time, and the fitting results are shown in Figure 9. It can be seen that the fitting accuracy of linear function, exponential function, and square root function is relatively low. Although the fitting accuracy of logarithmic function is the highest, its initial value is negative, which is not consistent with the actual situation. Therefore, the power function model was finally selected to describe the change of peak 


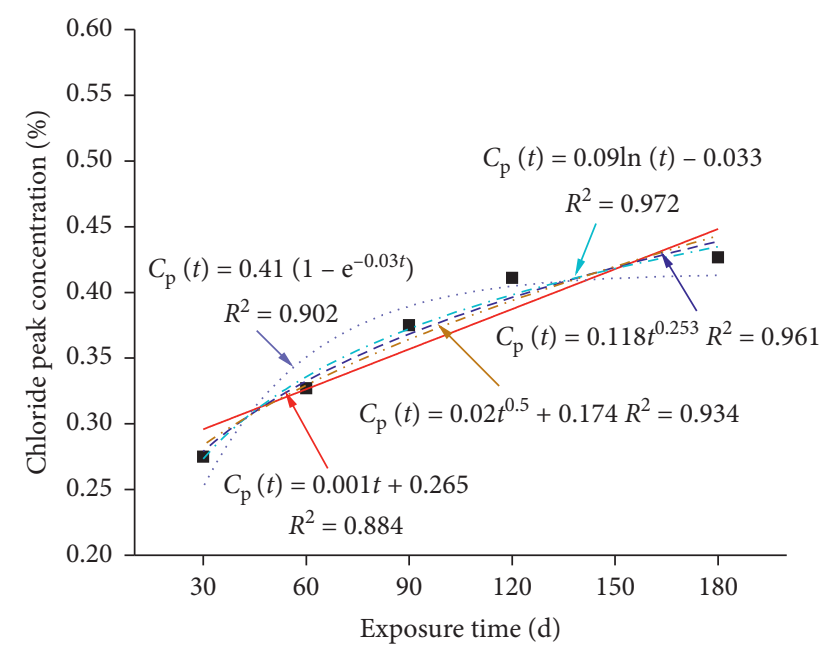

- $C_{\mathrm{p}}$ average value ….. Fitted curve (exponent)

_ Fitted curve (linear) _ - - Fitted curve (power)

.... Fitted curve ... Fitted curve

(square-root) (logarithmic)

FIGURE 9: Fitted curves of time-dependent chloride peak concentration.

chloride concentration of BPFRC with exposure time, as shown in the following equation:

$$
C_{\max }(t)=0.118 t^{0.253},
$$

where $C_{\max }(t)$ is the chloride peak concentration at different exposure times (\%) and $t$ is the exposure time of the BPFRC (d).

\subsection{Chloride Diffusion Coefficient of BPFRC}

3.4.1. Analysis of Factors Influencing Chloride Diffusion Coefficient. In concrete subjected to drying-wetting cycles, the concrete is unsaturated, and the convection zone and $C_{\max }$ are formed in the surface layer after the chloride ion has entered the concrete. The value of $D_{\mathrm{a}}$ calculated using Fick's second law is unreliable. Andrade et al. [40] proposed a novel method to calculate $D_{\mathrm{a}}$ that first removes the chloride ion increase stage, then calibrates the depth position coordinates with $C_{\max }$ as the zero point, and finally fits the descending section. Chang et al. [41] verified the suitability of this method for calculating $D_{\mathrm{a}}$ in concrete subjected to drying-wetting cycle. The equation to calculate $D_{\mathrm{a}}$ is as follows:

$$
C(x, t)=C_{0}+\left(C_{s, \Delta x}-C_{0}\right) \times\left[1-\operatorname{erf} \frac{x-\Delta x}{2 \sqrt{D_{a}(t) t}}\right],
$$

where $C(x, t)$ is the chloride concentration in concrete subjected to a drying-wetting duration $t$ and at a depth $x, C_{0}$ is the initial chloride concentration, $C_{s, \triangle x}$ is the chloride concentration at the depth of the convection zone, erf () is the error function, and $D_{\mathrm{a}}(t)$ is the apparent chloride diffusion coefficient.

$D_{\mathrm{a}}$ of the BPFRC specimens under different exposure times was calculated using (4), as shown in Figure 10. $D_{\mathrm{a}}$ for all the BPFRC specimens decreased with increase in the

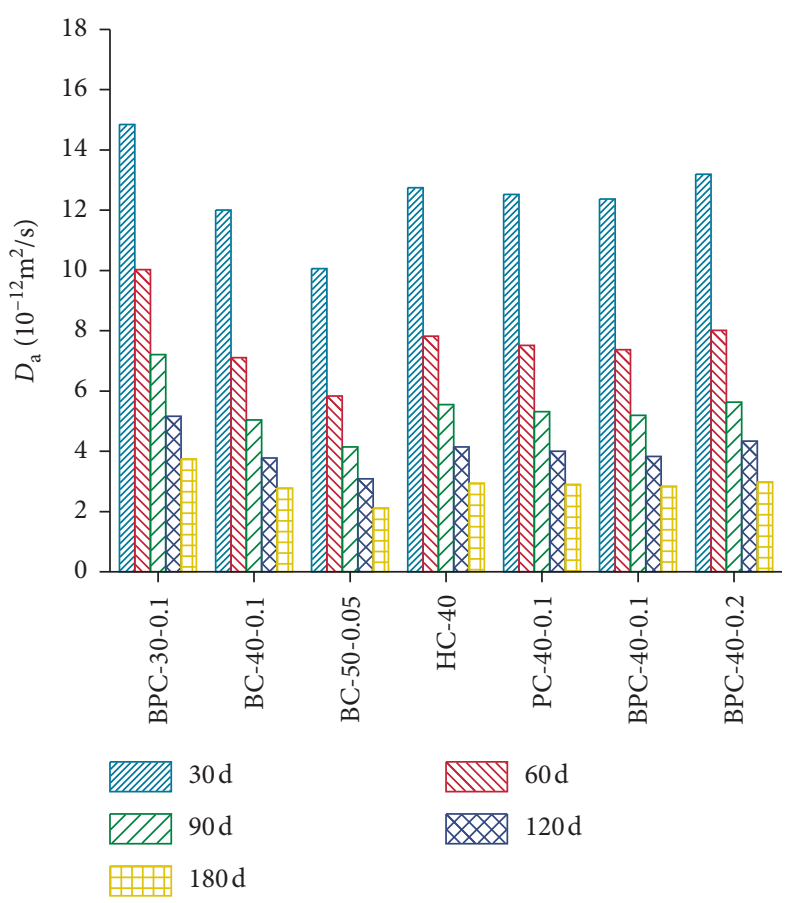

FIgURe 10: Apparent chloride diffusion coefficient of BPFRC.

exposure time. The strength grade had a significant effect on $D_{\mathrm{a}}$; the apparent chloride diffusion coefficient of BPFRC decreased with an increase in the strength grade. $D_{\mathrm{a}}$ of BPC30-0.1 after $30 \mathrm{~d}, 90 \mathrm{~d}$, and $180 \mathrm{~d}$ of erosion was $47.67 \%$, $73.99 \%$, and $77.09 \%$ higher than that of $\mathrm{BC}-50-0.05$, respectively. Concrete with a high strength grade has a lower porosity and denser matrix, which slows the diffusion rate of chloride ions. Compared to HC-40, after $30 \mathrm{~d}$ of erosion, $D_{\mathrm{a}}$ of BC-40-0.1, PC-40-0.1, BPC-40-0.1, and BPC-40-0.2 decreased by $5.79 \%, 1.75 \%, 2.91 \%$, and $-3.53 \%$, respectively; after $180 \mathrm{~d}$ of erosion, $D_{\mathrm{a}}$ of BC-40-0.1, PC-40-0.1, BPC-400.1 , and BPC-40-0.2 decreased by $5.38 \%, 1.54 \%, 3.45 \%$, and $-1.46 \%$, respectively. This indicates that the effect of fibers on $D_{\mathrm{a}}$ of concrete decreased with increase in the erosion time.

3.4.2. Multifactor Model of Apparent Chloride Diffusion Coefficient. To investigate the effects of the exposure time, strength grade, and fiber content on $D_{\mathrm{a}}$ of BPFRC, an apparent chloride diffusion coefficient model was established based on the multifactor method, as shown in the following equation:

$$
D_{a}(t, S, V)=D_{\text {ref }} \cdot f_{1}(t) \cdot f_{2}(S) \cdot f_{3}(V),
$$

where $D_{\mathrm{a}}(t, S, V)$ is the apparent chloride diffusion coefficient considering the exposure time, strength grade, and fiber content, respectively; $D_{\text {ref }}$ is the reference chloride diffusion coefficient; and $f_{1}(t), f_{2}(S)$, and $f_{3}(V)$ are the correction coefficients of the exposure time, strength grade, and fiber content, respectively.

(1) Time-Dependent Correction Factor $f_{1}(t)$. When only considering the time-dependent coefficient of $D_{\mathrm{a}}, D_{\mathrm{a}}$ model can be expressed as follows: 


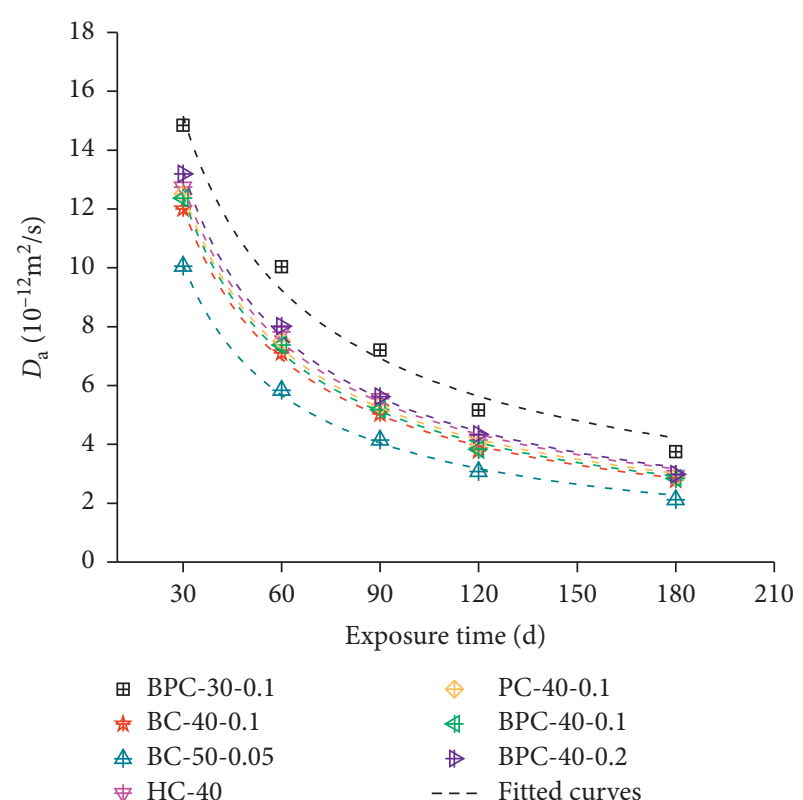

FIGURE 11: Relationship between apparent chloride diffusion coefficient and exposure time.

$$
D_{a}(t)=D_{\text {ref }}\left(\frac{t_{\mathrm{ref}}}{t}\right)^{m}
$$

where $t_{\text {ref }}$ is the reference time, usually $28 \mathrm{~d}$ [42], and $m$ is the time-dependent coefficient.

Time-dependent coefficient is an important parameter that affects the accuracy of concrete life prediction, which is usually related to strength grade, cementitious material, curing time, and exposure conditions [38]. The reference diffusion coefficient and time-dependent coefficient are calculated using (6), and the results are presented in Figure 11 and Table 5. It can be seen that the fitting accuracy values $R^{2}$ of all BPFRC specimens are greater than 0.95 . The higher the strength grade, the greater the timedependent coefficient $m$, indicating that the apparent chloride diffusion coefficient of concrete decreases rapidly with the increase of exposure time, which is consistent with the research results of Huang et al. [37]. Compared with the concrete without fiber, the influence of BF, PF, or hybrid BF-PF on time-dependent coefficient is less.

All BPFRC specimens were normalized according to C40 concrete (BC-40-0.1), i. e., reference chloride diffusion coefficient $D_{\text {ref }}=D_{\text {ref }} \quad(B C-40-0.1)=12.76 \times 10^{-12} \mathrm{~m}^{2} / \mathrm{s}$. The influence factor $f_{1}(t)$, considering the effect of exposure time on the apparent chloride diffusion coefficient, can be defined as follows:

$$
f_{1}(t)=\left(\frac{t_{\mathrm{ref}}}{t}\right)^{m}
$$

The influence coefficient of strength grade and fibers (BF and PF) content on time-dependent coefficient $m$ can be expressed as follows:

$$
m(S, V)=0.81 \cdot k_{S} \cdot k_{V},
$$

where $k_{S}$ and $k_{\mathrm{V}}$ are the correction coefficients of strength grade and fiber content.

(2) Strength Grade Correction Factor $f_{2}(S)$. The correction factor $f_{2}(S)$, considering the effect of strength grade on the apparent chloride diffusion coefficient, can be defined as follows:

$$
f_{2}(S)=\frac{D_{\text {ref }}(S)}{D_{\text {ref }}}
$$

where $\mathrm{D}_{\text {ref }}(S)$ is the reference chloride diffusion coefficient with different strength grade.

(3) Fiber Content Correction Factor $f_{3}(V)$. The correction factor $f_{3}(V)$, considering the effect of fiber contents (BF and $\mathrm{PF}$ ) on the apparent chloride diffusion coefficient, is defined as follows:

$$
f_{3}(V)=\frac{D_{\text {ref }}(V)}{D_{\text {ref }}},
$$

where $\mathrm{D}_{\text {ref }}(V)$ is the reference chloride diffusion coefficient with various fiber contents of $\mathrm{BF}$ and $\mathrm{PF}$.

Based on the regression analysis of the test results, the multifactor model of apparent chloride diffusion coefficient for BPFRC considering exposure time, strength grade, and fiber content is established as follows:

$$
\left\{\begin{array}{l}
D_{\mathrm{a}}(t, S, V)=D_{\mathrm{ref}} \cdot f_{1}(\mathrm{t}) \cdot f_{2}(\mathrm{~S}) \cdot f_{3}(\mathrm{~V}), \\
D_{\mathrm{ref}}=\frac{12.76 \times 10^{-12} \mathrm{~m}^{2}}{s}, \\
f_{1}(\mathrm{t})=\left(\frac{t_{\mathrm{ref}}}{t}\right)^{0.81\left(0.31 S^{0.32}\right) \cdot\left(0.97+0.29 V_{\mathrm{B}}+0.19 V_{\mathrm{P}}\right)}, \\
f_{2}(\mathrm{~S})=2.24 e^{-0.02 S}, \\
f_{3}(V)=1.08-0.81 V_{B}-0.37 V_{P},
\end{array}\right.
$$

where $S$ is the strength grade and $V_{\mathrm{B}}$ and $V_{\mathrm{P}}$ are the $\mathrm{BF}$ and PF content.

The relationship between the predicted and experimental values of $D_{\mathrm{a}}$ of the BPFRC specimens at various exposure times is shown in Figure 12. The error between the predicted values of the model and the experimental values is less than $15 \%$, which satisfies the error requirements. Therefore, the proposed model can be used to predict $D_{\mathrm{a}}$ of BPFRC subjected to drying-wetting cycles.

3.5. Theoretical Pore Volume of BPFRC. Figure 13 presents the theoretical pore volume of the BPFRC specimens at different erosion times. It can be seen that the theoretical pore volume of the BPFRC specimens initially decreased and then increased with the increase in the erosion time. The theoretical pore volume of the BPFRC specimens was the least after $30 \mathrm{~d}$ of erosion. During the initial stages of the 
TABLE 5: Reference chloride diffusion coefficient and time-dependent coefficient of BPFRC.

\begin{tabular}{lccr}
\hline Mixture & $D_{\text {ref }}\left(10^{-12} \mathrm{~m}^{2} / \mathrm{s}\right)$ & $\mathrm{m}$ & $R^{2}$ \\
\hline BPC-30-0.1 & 15.92 & 0.71 & 0.98 \\
BC-40-0.1 & 12.76 & 0.81 & 0.99 \\
BC-50-0.05 & 10.72 & 0.83 & 0.99 \\
HC-40 & 13.58 & 0.78 & 0.99 \\
PC-40-0.1 & 13.32 & 0.79 & 1.00 \\
BPC-40-0.1 & 13.17 & 0.80 & 1.00 \\
BPC-40-0.2 & 14.05 & 0.79 & 0.99 \\
\hline
\end{tabular}

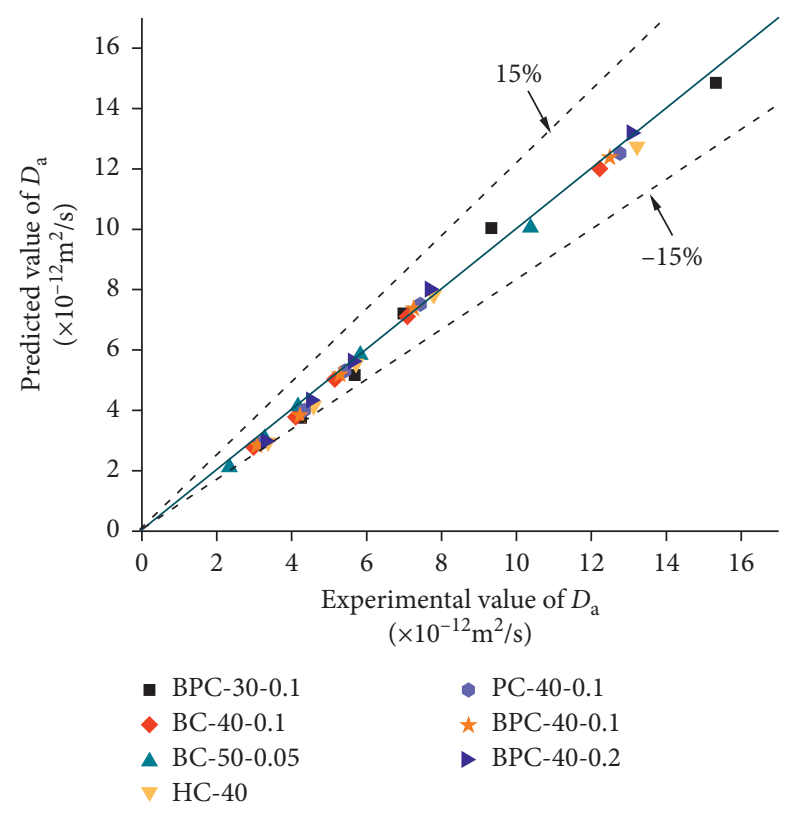

FIGURE 12: Comparison between predicted and experimental values of (D) $)_{\mathrm{a}}$ for the BPFRC.

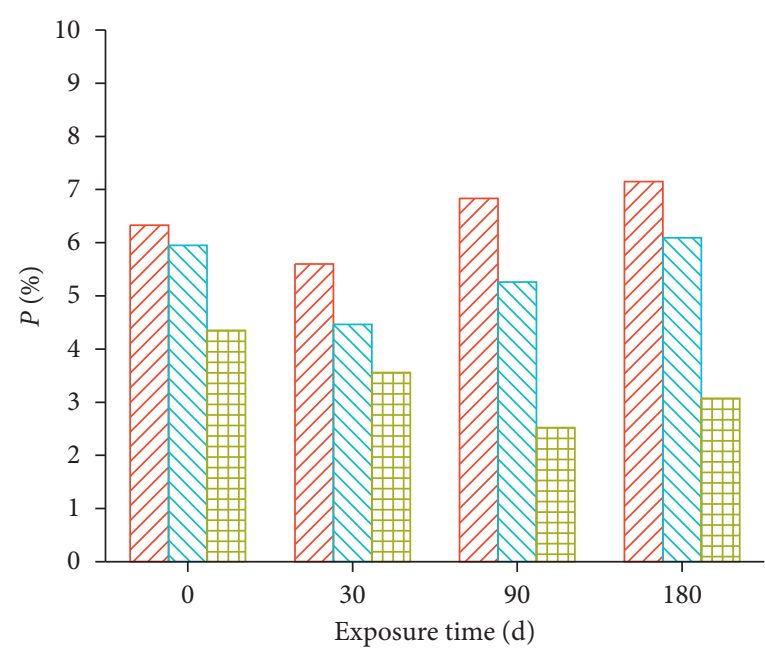

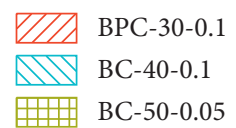
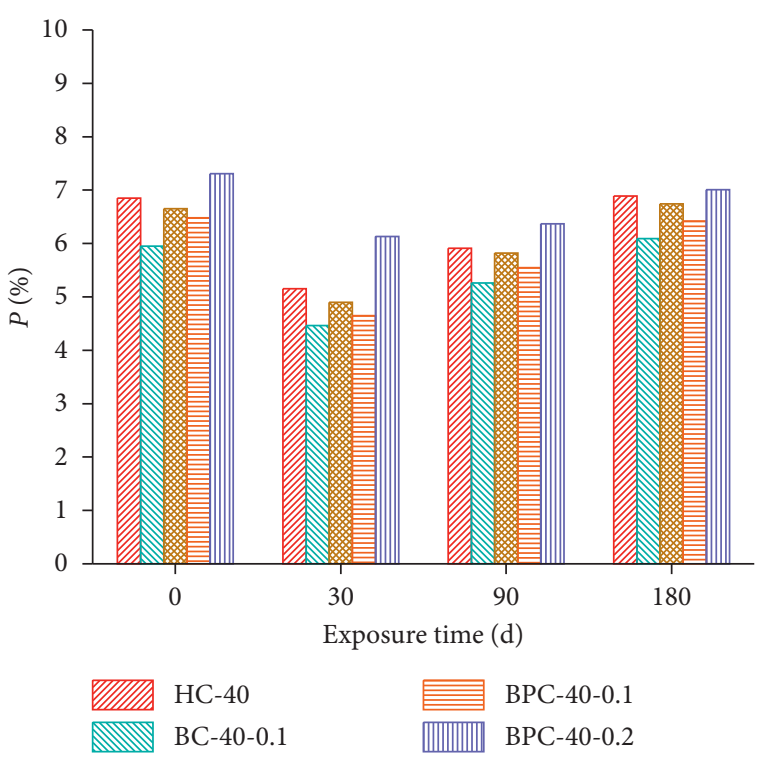

(b)

FIgURE 13: Theoretical pore volume of BPFRC. (a) Different strength grades. (b) Different fiber types and contents. 


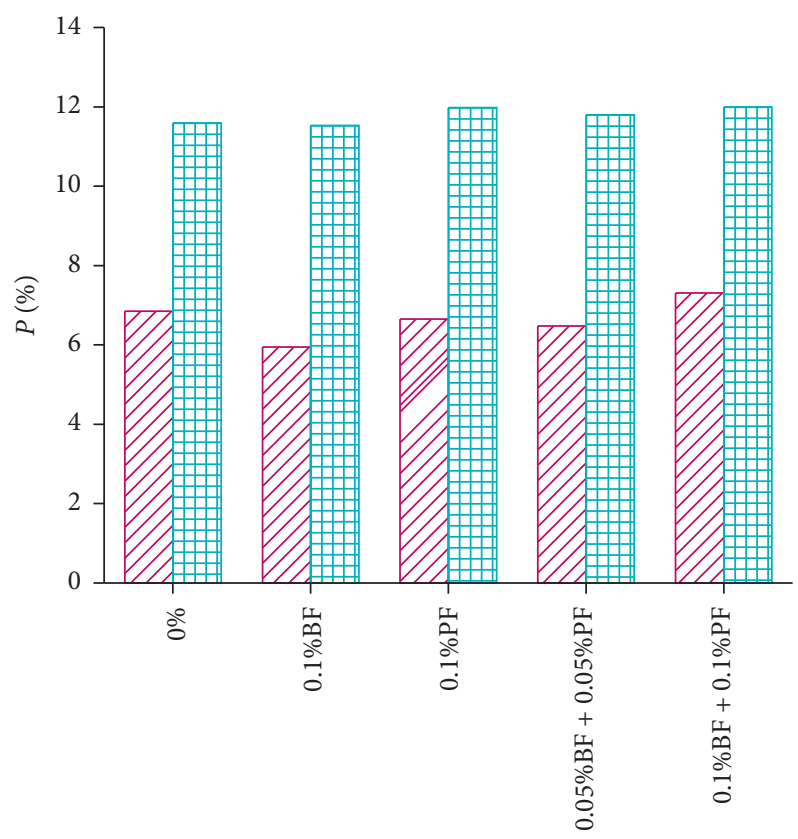

VI/ TG method

世团 MIP method

FIgURE 14: Comparison of pore volume of BPFRC [43].

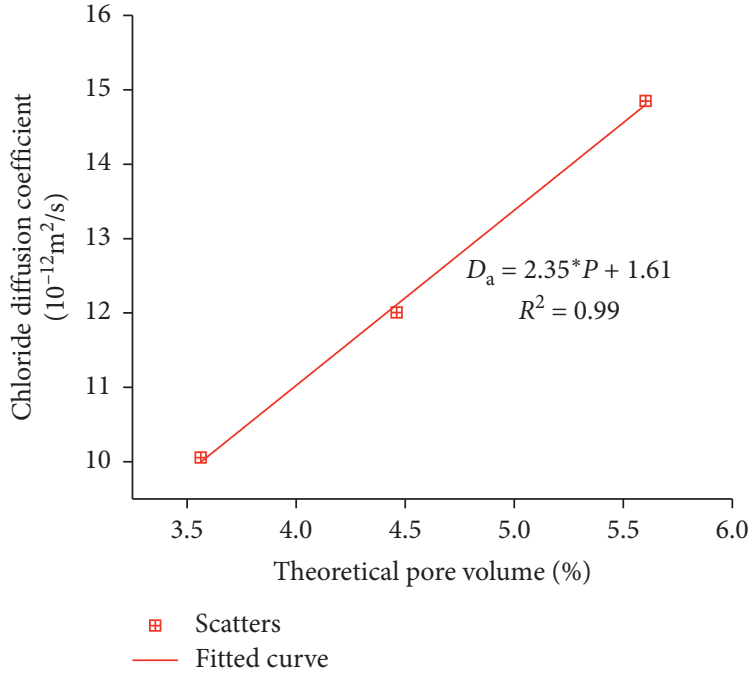

(a)

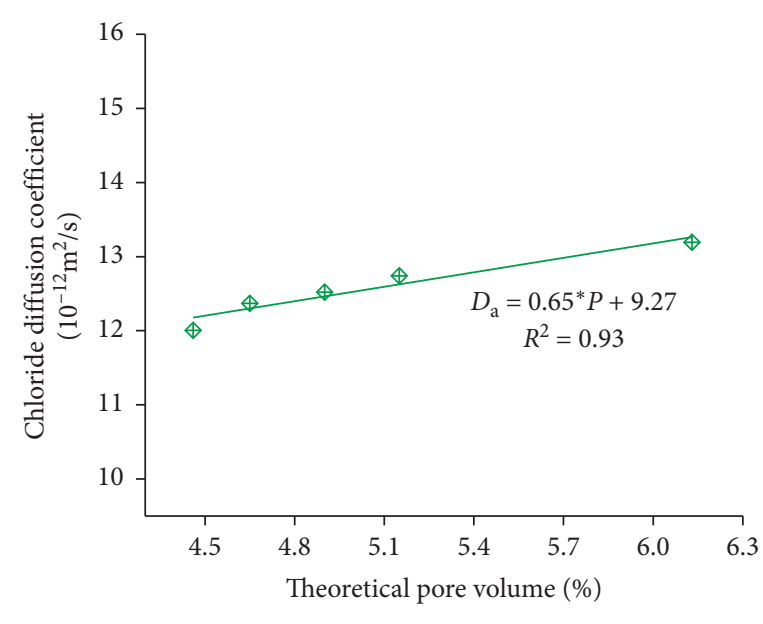

$\star$ Scatters

Fitted curve

(b)

FIgURE 15: Relationship between theoretical pore volume and (D) after $30 \mathrm{~d}$ of erosion. (a) Different strength grades. (b) Different fiber types and contents.

erosion, the continuous hydration of concrete and the formation of Friedel's salt by the chloride ions and the hydration products reduce the theoretical total pore volume of BPFRC. As the erosion time increases, alkali substances in the concrete such as $\mathrm{Ca}(\mathrm{OH})_{2}, \mathrm{NaOH}$, and $\mathrm{KOH}$ continuously dissolved, and the concrete matrix structure becomes loose. Consequently, the theoretical total pore volume increases. As shown in Figure 13(a), the theoretical total pore volume decreased with the increase in strength grade. After $180 \mathrm{~d}$ of erosion, the theoretical total pore volume of C30 concrete (BPC-30-0.1) was 1.17 times and 2.32 times that of C40 concrete (BC-40-0.1) and C50 concrete (BC-50-0.05), respectively.

The effects of BF and PF and hybrid BF-PF on the theoretical pore volume of concrete are shown in Figure 13(b). Before the erosion, the theoretical pore volume 

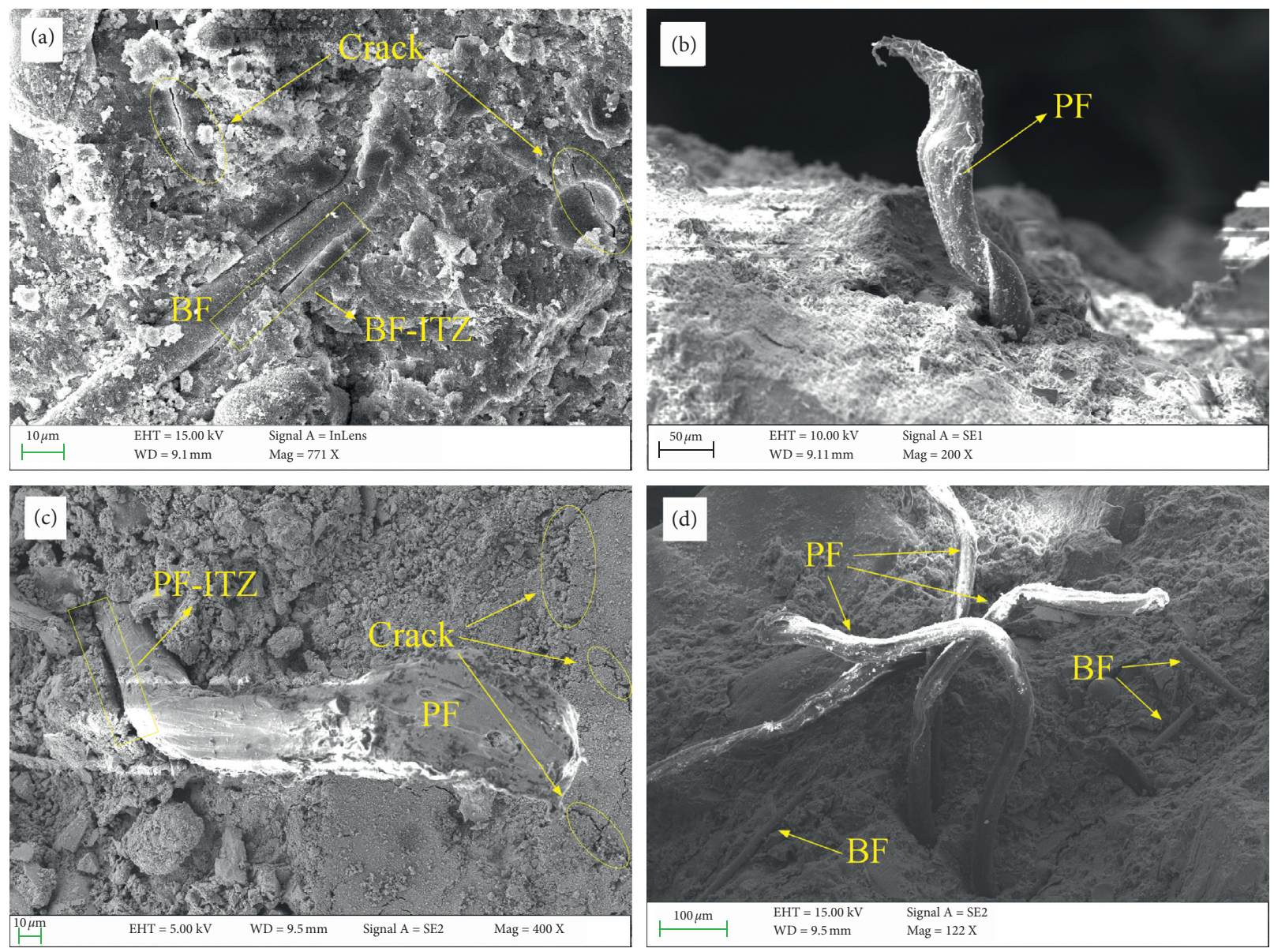

Figure 16: FE-SEM micrographs of BF and PF in BPFRC. (a) The interface between the BF and matrix. (b) Failure modes of PF. (c) The interface between the PF and matrix. (d) Distribution pattern of BF and PF with $0.2 \%$ hybrid fiber.

of the BC-40-0.1, PC-40-0.1, BPC-40-0.1, and BPC-40-0.2 specimens was $13.13 \%, 2.91 \%, 5.41 \%$, and $-6.71 \%$ lower than that of HC-40, respectively. After $180 \mathrm{~d}$ of erosion, the theoretical pore volumes of BC-40-0.1, PC-40-0.1, BPC-400.1 , and BPC-40-0.2 were $11.61 \%, 2.17 \%, 6.82 \%$, and $-1.74 \%$ lower than that of $\mathrm{HC}-40$. Compared to the concrete with single $\mathrm{BF}$, the bonding performance between the $\mathrm{PF}$ and the concrete matrix is poor, which increases the theoretical pore volume of PC-40-0.1. When BF and PF are mixed and the fiber content is $0.1 \%$, the two fibers have a certain degree of influence on the mixing process, and the dispersion and cohesiveness of the fiber are reduced. Consequently, the theoretical pore volume of BPC-40-0.1 is slightly larger than that of BC-40-0.1. However, when BF and PF are mixed with a fiber content of $0.2 \%$, the interface between the fiber and concrete matrix increases due to the excessive amount of fiber. The uneven dispersion leads to a decrease in adhesion, increasing the theoretical pore volume of the concrete.

Niu et al. [43] measured the cumulative pore volume of basalt-polypropylene fiber concrete with different fiber content by Mercury intrusion porosimetry (MIP), and the cumulative pore volume is shown in Figure 14. It can be seen that the pore volume measured by Mercury porosimetry is $11.59 \%-14.59 \%$, which is larger than that calculated by TG. This is because the pore size that can be measured using MIP technique is in the range of $0.005 \mu \mathrm{m}-1000 \mu \mathrm{m}$, including gel pores, capillaries, and large pores, while the total pore volume calculated by TG is the pore volume formed by free water evaporation. Fallah and Nematzadeh [44] calculated the porosity of polymer and polypropylene fiber concrete according to capillary water absorption, and the porosity is $7.0 \%-9.39 \%$, which is slightly higher than that of concrete of the same strength grade in this study. In addition to the different testing methods of pore volume, in this study, the addition of mineral admixtures can improve the degree of hydration of concrete and generate more bound water, thus reducing the content of free water, which is also the reason for the decrease of porosity of concrete.

The relationship between the theoretical pore volume of the BPFRC and $D_{\mathrm{a}}$ after $30 \mathrm{~d}$ of erosion is shown in Figure 15. As shown, a good correlation exists between the theoretical pore volume and $D_{\mathrm{a}} . D_{\mathrm{a}}$ increases with the increase in the theoretical pore volume. The lower the theoretical pore volume, the better the compactness of concrete, and the smaller the chloride ion transport rate in concrete. Therefore, concrete presents excellent chloride resistance.

3.6. FE-SEM Analysis. To analyze the effect of BF and PF on chloride transport performance of BPFRC, the morphology 

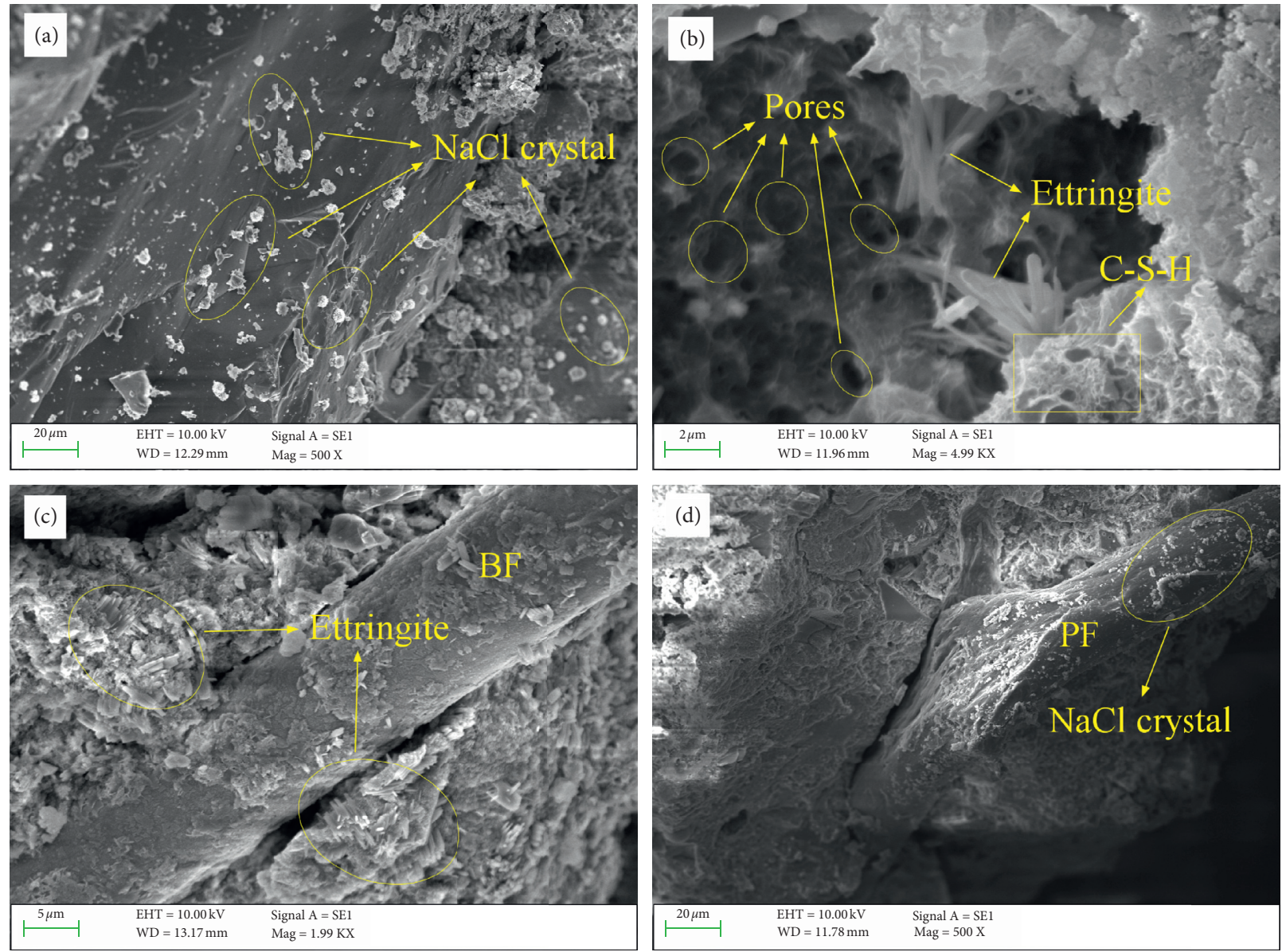

Figure 17: FE-SEM micrographs of BPC-40-0.1 concrete after 180 days of exposure time. (a) Sodium chloride crystals. (b) Corrosion products. (c) The interface between the BF and concrete matrix. (d) The interface between the PF and concrete matrix.

of BPFRC was observed by FE-SEM. Figure 16 shows the distribution of $\mathrm{BF}$ and $\mathrm{PF}$ in BPFRC without erosion. It can be seen from Figure 16(a) that a certain amount of hydration products are attached to the surface of $\mathrm{BF}$, the interface structure of $\mathrm{BF}$ is dense, and the bond between $\mathrm{BF}$ and matrix is tight; there are microcracks distributed around $\mathrm{BF}$, and there is no connection between microcracks, indicating that the addition of $\mathrm{BF}$ can effectively restrain the emergence and development of shrinkage cracks in concrete at the initial stage of hydration. The distribution of PF in concrete is shown in Figures 16(b) and 16(c). It can be seen that, compared with $\mathrm{BF}, \mathrm{PF}$ has poor bonding performance with concrete matrix, and there is obvious gap between fiber and matrix. PF warps at the end after tension, and PF can consume a certain amount of fracture energy in the process of tension, which can restrain the development of cracks [45]. Figure 16(d) presents the fiber distribution of BPC-400.2 concrete. It can be seen that the fiber dispersion is uneven due to excessive fiber content. The bonding performance between the fibers and the concrete matrix decreases, which not only increases the weak interface between fiber and concrete matrix and reduces the compactness of concrete but also weakens the inhibition and control effect of fiber on cracks, thus providing more channels for the transport of chloride ions. Therefore, there are more chloride ions in BPC-40-0.2 concrete.

The morphology of BPC-40-0.1 concrete after $180 \mathrm{~d}$ of erosion is shown in Figure 17. As shown in Figures 17(a) and 17(b), a large number of sodium chloride crystals are distributed in BPFRC, and the hydration products exhibit loose and porous characteristics due to decalcification, forming many small pores. It can be seen from Figure 17(c) that salt crystallization and corrosion products are attached to the surface of BF and the fiber-matrix interface transition zone, but the bond strength between fiber and matrix decreases, which is due to the decrease of alkalinity of pore solution and serious loss of hydration products in concrete after erosion. Figure 17(d) shows the morphology of PF in concrete after erosion. Sodium chloride crystals exist on the fiber surface, but there are few hydration products attached around the fiber.

\section{Conclusions}

In this study, a tropical ocean tidal zone was simulated using a drying-wetting cycle test system in a high-temperature environment. The effects of the strength grade, fiber type, and fiber content on the chloride transport performance of 
BPFRC were investigated. The main conclusions are as follows:

(1) The pore solution $\mathrm{pH}$ of the BPFRC specimens decreased with the increase in the exposure time, and the pore solution $\mathrm{pH}$ of the surface concrete decreased rapidly. In the process of erosion, the $\mathrm{pH}$ decrease rate of high strength concrete was slower, and the rising range of $\mathrm{pH}$ was smaller. The effects of $\mathrm{BF}, \mathrm{PF}$, and hybrid $\mathrm{BF}-\mathrm{PF}$ on the pore solution $\mathrm{pH}$ of C40 concrete are as follows: BC-40-0.1>BPC-400.1>PC-40-0.1> HC-40>BPC-40-0.2.

(2) The chloride concentration at a given depth in the BPFRC specimens increased gradually with the increase in the exposure time; it increased rapidly initially and gradually during the later stages. The strength and fiber had little effect on the depth of convection zone, and the depth of convection zone of all specimens at each erosion time was $2 \mathrm{~mm}$. The chloride concentration in the BPFRC specimens decreased with the increase in strength grade. At a fiber volume content of $0.1 \%$, the single-doped BF had the largest effect on reducing the BPFRC chloride concentration in the $\mathrm{C} 40$ concrete. The effect of the hybrid BF-PF on the reduction of the chloride concentration was between those of the BF alone or PF alone. When the hybrid fiber content was $0.2 \%$, the addition of fibers increased the chloride concentration at a given depth in the concrete.

(3) The chloride concentration of BPFRC presented a two-stage distribution, and the chloride peak concentration appeared at the depth of $2 \mathrm{~mm}$. $C_{\max }$ in C30 concrete (BPC-30-0.1) was $16.78 \%-22.61 \%$ and $33.23 \%-48.84 \%$ higher than that of $\mathrm{BC}-40-0.1$ and BC-50-0.05, respectively. $C_{\max }$ of C40 concrete with $0.1 \% \mathrm{BF}$ was the lowest, which was $5.95 \%-3.24 \%$ lower than that of the specimen without fiber (HC40 ). The addition of $0.2 \%$ hybrid fiber increased $C_{\max }$ of C40 concrete by $0.93 \%-3.21 \%$.

(4) The chloride peak concentration increased with the exposure time. The power function was regarded as the best fitting formula to describe the chloride peak concentration model of BPFRC.

(5) $D_{\mathrm{a}}$ of the BPFRC specimens decreased with the increase of exposure time, exhibiting a power function attenuation law. $D_{\mathrm{a}}$ of C30 concrete (BPC-30-0.1) was $47.67 \%-77.09 \%$ higher than that of $\mathrm{C} 50$ concrete (BC-50-0.05). With the increase of erosion time, the decreasing effect of single fiber on $D_{\mathrm{a}}$ of concrete decreased, while that of hybrid fiber increased. A multifactor model was established considering the effects of exposure time, strength grade, and the content of $\mathrm{BF}$ and PF on $D_{\mathrm{a}}$ of BPFRC. The error between the calculated and experimental values of apparent chloride diffusion coefficient was within $15 \%$.

(6) The theoretical pore volume of the BPFRC specimens initially decreased and then increased with the exposure time increasing. The higher the strength grade, the smaller the theoretical pore volume. BF, $\mathrm{PF}$, and hybrid BF-PF had positive and negative effects on the theoretical pore volume of the C40 concrete. After $180 \mathrm{~d}$ of erosion, the addition of fiber reduced the porosity of C40 concrete by $11.61 \%$ to $-1.74 \%$. The theoretical pore volume demonstrated good correlation with $D_{\mathrm{a}}$.

(7) FE-SEM results showed that the bond between $\mathrm{BF}$ and concrete matrix was better than that of PF before erosion, which could effectively control the development of microcracks. For the specimen containing $0.2 \%$ hybrid fiber, BF and PF presented agglomeration and uneven dispersion. After $180 \mathrm{~d}$ of erosion, a large number of salt crystals were distributed in BPFRC, and the bonding properties between fiber and matrix decreased.

\section{Data Availability}

The data used to support the findings of this study are included within the article.

\section{Conflicts of Interest}

The authors declare that they have no conflicts of interest.

\section{Acknowledgments}

This research was funded by the National Natural Science Foundation of China (Grant no. 51590914) and the Natural Science Foundation of Shaanxi Province (Grant no. 2019JQ481).

\section{References}

[1] W. L. Jin and Y. X. Zhao, Durability of Concrete Structures, Science Press, Beijing, China, 2014.

[2] P. Rashiddadash, A. A. Ramezanianpour, and M. Mahdikhani, "Experimental investigation on flexural toughness of hybrid fiber reinforced concrete (HFRC) containing metakaolin and pumice," Construction and Building Materials, vol. 51, pp. 313-320, 2014.

[3] O. Kayali, M. N. Haque, and B. Zhu, "Some characteristics of high strength fiber reinforced lightweight aggregate concrete," Cement and Concrete Composites, vol. 25, no. 2, pp. 207-213, 2003.

[4] D.-Y. Yoo and N. Banthia, "Mechanical properties of ultrahigh-performance fiber-reinforced concrete: a review," $\mathrm{Ce}$ ment and Concrete Composites, vol. 73, pp. 267-280, 2016.

[5] K. G. Kuder and S. P. Shah, "Processing of high-performance fiber-reinforced cement-based composites," Construction and Building Materials, vol. 24, no. 2, pp. 181-186, 2010.

[6] H. M. Vogel and D. "Svecova, "Evaluation of elastic modulus for high-strength concrete," ACI Materials Journal, vol. 109, no. 3, pp. 313-322, 2012.

[7] J. Thomas and A. Ramaswamy, "Mechanical properties of steel fiber-reinforced concrete," Journal of Materials in Civil Engineering, vol. 19, no. 5, pp. 385-392, 2007.

[8] B. H. Oh, D. G. Park, J. C. Kim, and Y. C. Choi, "Experimental and theoretical investigation on the postcracking inelastic 
behavior of synthetic fiber reinforced concrete beams," Cement and Concrete Research, vol. 35, no. 2, pp. 384-392, 2005.

[9] C. Rooban, V. Srikanth, and P. Indubhushan, "Mechanical properties of high volume fly ash concrete reinforced with hybrid fibers," Advances in Materials Science and Engineering, vol. 2016, Article ID 1638419, 7 pages, 2016.

[10] M. Hsie, C. Tu, and P. S. Song, "Mechanical properties of polypropylene hybrid fiber-reinforced concrete," Materials Science and Engineering: A, vol. 494, no. 1-2, pp. 153-157, 2008.

[11] M. Pajak, "Investigation on flexural properties of hybrid fibre reinforced self-compacting concrete," Procedia Engineering, vol. 161, pp. 121-126, 2016.

[12] C. J. Yang, C. K. Huang, Y. Che, and B. X. Wang, "Mechanical properties and impermeability of hybrid fiber reinforced concrete," Journal of Building Materials, vol. 11, pp. 89-93, 2008.

[13] V. Fiore, T. Scalici, G. Di Bella, and A. Valenza, "A review on basalt fibre and its composites," Composites Part B: Engineering, vol. 74, pp. 74-94, 2015.

[14] D. C. Liu, Study on the Properties of Basalt and Polypropylene Mixed Fiber Concrete, M. S. Thesis, Chongqing Jiaotong University, Chongqing, China, 2018.

[15] M. Nili and V. Afroughsabet, "The long-term compressive strength and durability properties of silica fume fiber-reinforced concrete," Materials Science and Engineering: A, vol. 531, pp. 107-111, 2012.

[16] P. Zhang and Q.-f. Li, "Effect of polypropylene fiber on durability of concrete composite containing fly ash and silica fume," Composites Part B: Engineering, vol. 45, no. 1, pp. 1587-1594, 2013.

[17] J. Yuan, Y. Liu, Z. Tan, and B. Zhang, "Investigating the failure process of concrete under the coupled actions between sulfate attack and drying-wetting cycles by using X-ray CT," Construction and Building Materials, vol. 108, pp. 129-138, 2016.

[18] O. Helson, J. Eslami, A.-L. Beaucour, A. Noumowe, and P. Gotteland, "Durability of soil mix material subjected to wetting/drying cycles and external sulfate attacks," Construction and Building Materials, vol. 192, pp. 416-428, 2018.

[19] T. Simcic, S. Pejovnik, G. De Schutter, and V. B. Bosiljkov, "Chloride ion penetration into fly ash modified concrete during wetting-drying cycles," Construction and Building Materials, vol. 93, pp. 1216-1223, 2015.

[20] M. H. F. Medeiros, A. Gobbi, G. C. Réus, and P. Helene, "Reinforced concrete in marine environment: effect of wetting and drying cycles, height and positioning in relation to the sea shore," Construction and Building Materials, vol. 44, pp. 452-457, 2013.

[21] J. Liu, Y. Jia, and J. Wang, "Calculation of chloride ion diffusion in glass and polypropylene fiber-reinforced concrete," Construction and Building Materials, vol. 215, pp. 875-885, 2019.

[22] O. Karahan and C. D. Atiş, "The durability properties of polypropylene fiber reinforced fly ash concrete," Materials \& Design, vol. 32, no. 2, pp. 1044-1049, 2011.

[23] M. Osama and A. H. Waddah, "Influence of fly ash and basalt fibers on strength and chloride penetration resistance of selfconsolidating concrete," Materials Science Forum, vol. 866, 2016.

[24] Y. Guo, X. Hu, and J. Lv, "Experimental study on the resistance of basalt fibre-reinforced concrete to chloride penetration," Construction and Building Materials, vol. 223, pp. 142-155, 2019.
[25] China Architecture and Building Press, Technical Specification for Test of Chloride Ion Content in Concrete, China Architecture \& Building Press, Beijing, China, 2013.

[26] J. B. Wang and D. T. Niu, "Investigation of chloride ion diffusion in shotcrete under bending loading," China Civil Engineering Journal, vol. 51, no. 120, pp. 95-102, 2018.

[27] S. Diamond, "Mercury porosimetry," Cement and Concrete Research, vol. 30, no. 10, pp. 1517-1525, 2000.

[28] C. Gallé, "Effect of drying on cement-based materials pore structure as identified by mercury intrusion porosimetry," Cement and Concrete Research, vol. 31, no. 10, pp. 1467-1477, 2001.

[29] M. Zajac, S. Hoock, C. Stabler, and M. Ben Haha, "Effect of hydration kinetics on properties of compositionally similar binders," Cement and Concrete Research, vol. 101, pp. 13-24, 2017.

[30] H. M. Hu and B. G. Ma, Concrete Mineral Admixture, China Electric Power Press, Beijing, China, 2016.

[31] B. Chen and J. Liu, "Contribution of hybrid fibers on the properties of the high-strength lightweight concrete having good workability," Cement and Concrete Research, vol. 35, no. 5, pp. 913-917, 2005.

[32] S. Arivalagan, "Study on the compressive and split tensile strength properties of basalt fibre concrete members," Global Journal of Research in Engineering, vol. 12, pp. 23-27, 2012.

[33] P. S. Mangat and B. T. Molloy, "Prediction of long term chloride concentration in concrete," Materials and Structures, vol. 27, no. 6, pp. 338-346, 1994.

[34] C. T. Sun and D. T. Niu, "Experimental study on chloride diffusion properties of concrete in freeze-thaw environment," Bulletin of Chinese Ceramic Society, vol. 33, no. 8, pp. 18631869, 2014.

[35] A. Ghazy, M. T. Bassuoni, E. Maguire, and M. O’Loan, "Properties of fiber-reinforced mortars incorporating nanosilica," Fiber, vol. 6, pp. 1-16, 2016.

[36] Y. X. Zhao, C. K. Wang, W. L. Jin, and C. Xu, "Experimental analysis on time-dependent law of surface chloride ion concentration of concrete," Journal of Civil Architectural and Environmental Engineering, vol. 32, no. 3, pp. 8-13, 2010.

[37] D. G. Huang, D. T. Niu, L. Su, and Q. Fu, "Chloride diffusion behavior of coral aggregate concrete under drying-wetting cycles," Construction And Building Materials, vol. 270, Article ID 121485, 2020.

[38] S.-W. Pack, M.-S. Jung, H.-W. Song, S.-H. Kim, and K. Y. Ann, "Prediction of time dependent chloride transport in concrete structures exposed to a marine environment," Cement and Concrete Research, vol. 40, no. 2, pp. 302-312, 2010.

[39] Y.-r. Zhang, Y. Zhang, J. Huang, H.-x. Zhuang, and J.-z. Zhang, "Time dependence and similarity analysis of peak value of chloride concentration of concrete under the simulated chloride environment," Construction and Building Materials, vol. 181, pp. 609-617, 2018.

[40] C. Andrade, M. A. Climent, and G. de Vera, "Procedure for calculating the chloride diffusion coefficient and surface concentration from a profile having a maximum beyond the concrete surface," Materials and Structures, vol. 48, no. 4, pp. 863-869, 2015.

[41] H. L. Chang, S. Mu, Y. J. Liu, and J. Z. Liu, "Chloride profile with a chloride concentration peak and calculating methods of its diffusion parameters," Bulletin of Chinese Ceramic Society, vol. 36, no. 1, pp. 14-19, 2017. 
[42] M. D. A. Thomas and P. B. Bamforth, "Modelling chloride diffusion in concrete," Cement and Concrete Research, vol. 29, no. 4, pp. 487-495, 1999.

[43] D. Niu, D. Li, and Q. Fu, "A 3D-IFU model for characterising the pore structure of hybrid fibre-reinforced concrete," $M a$ terials \& Design, vol. 188, Article ID 108473, 2020.

[44] S. Fallah and M. Nematzadeh, "Mechanical properties and durability of high-strength concrete containing macro-polymeric and polypropylene fibers with nano-silica and silica fume," Construction and Building Materials, vol. 132, pp. 170-187, 2017.

[45] C. Jiang, K. Fan, F. Wu, and D. Chen, "Experimental study on the mechanical properties and microstructure of chopped basalt fibre reinforced concrete," Materials \& Design, vol. 58, no. 1, pp. 187-193, 2014. 